\title{
Scarcity and Survival: The Role of Oral Tradition in Mediating Subsistence Crises
}

\author{
LEAH D. MinC \\ Museum of Anthropology, University of Michigan, Ann Arbor, Michigan 48109
}

Received March 15, 1985

\begin{abstract}
Survival of periodic subsistence crises is largely dependent on a group memory of past crisis situations and of the strategies appropriate for dealing with the altered environmental conditions. One mechanism utilized by nonliterate societies for the preservation of survival knowledge is its incorporation in oral tradition. As a body of reference knowledge, oral traditions potentially operate over two time scales. Secular oral traditions (folktales, songs, and histories) depend on repetition for perpetuation with inherent potential for distortion. In contrast, sanctified oral traditions, such as ritual performances, rely on a correct reproduction of the ritual order to achieve supernatural efficacy. Rituals accordingly assume an invariant character appropriate for the transmission of survival information over extended periods of time. The role of oral tradition in mediating subsistence crises is examined for two hunter-gatherer groups: the Tareumiut and Nunamiut of northwest Alaska. Utilizing the ecological and ethnographic literature, the temporal variability in the primary faunal resources of these groups is modeled and the social means for buffering subsistence stress are presented. The survival strategies encoded in secular and sanctified forms of oral tradition are then evaluated and compared. The study concludes that secular forms provide a readily available medium for the enculturation of specific values or behaviors relating to group survival across seasonal or short-term interannual shortages, while ritual performances provide a model of resource variability and the appropriate responses relevant to crisis situations recurring on the pan-generational time scale. 1986 Academic Press, Inc.
\end{abstract}

\section{THEORETICAL CONSIDERATIONS}

Recurrent scarcity was a fact of life for many hunter-gatherer societies (Colson 1979). Balancing the view of hunter-gatherers as the "original affluent society" (Sahlins 1972:37) are those longer term studies of hunter-gatherer adaptations which suggest that even groups commanding an apparent abundance of resources lived sufficiently close to the margins of subsistence that variations in productivity could threaten hardship for the population (Bishop 1978; Cove 1978; Piddocke 1965; Sheehan 1985; Smith 1978). Recognition of the extent of economic uncertainty in hunter-gatherer subsistence has generated an increasing in- 
terest in the means by which simple sociocultural systems survive recurrent resource crises (Halstead et al. 1984; Jochim 1981; Laughlin and Brady 1978).

The present study examines the informational basis of long-term survival in hunter-gatherer societies. Current ecological models of huntergatherer subsistence, although productive sources for evaluating shortterm adaptive strategies, are considered unsatisfactory for modeling responses to longer term resource fluctuations for which prior knowledge of alternative strategies for survival cannot be assumed. It is suggested here that survival of environmental crises or resource collapse is largely dependent on a group memory of past crisis situations and of the strategies appropriate for dealing with the altered environmental conditions. One potential mechanism for transmitting information across different spans of time, that of "oral tradition," is explored here, as this medium serves to relate the participants within a cultural system to periodic fluctuations in their physical environment. The ethnographic and ecological literature is examined for two economically interdependent hunter-gatherer groups: the Tareumiut and the Nunamiut of northwest Alaska. First, the temporal variability of their respective subsistence resource bases is characterized. The informational content of various classes of oral tradition regarding that resource variability is then assessed.

\section{Resource Variability and Hunter-Gatherer Response}

The study of hunter-gatherer response to spatiotemporal variability in resource availability has been guided recently by the set of integrated models referred to as optimal foraging or optimal diet theory (Jochim 1976; Winterhalder and Smith 1981). Although optimal foraging models have made little direct contribution to the study of information processing in hunter-gatherer societies, this literature has established information processes as fundamental in the survival and adaptation of simple sociocultural systems.

Optimal foraging models are based on an assumed capacity for "adaptive decision making" on the part of individuals and cultures. This assumption maintains that hunter-gatherer subsistence practices are the result of deliberate decisions between alternative choices or strategies. On the basis of cross-culturally observed regularities, the economic decision-making behavior of hunter-gatherers is characterized as rational and satisficing, albeit based on partial uncertainty (Jochim 1976). That is, assuming an adequate antecedent state of knowledge concerning choices, an individual or group will decide to employ one or more strategies according to the perceived degree of fit between the estimated outcome of the strategy and a preconceived set of nutritional, caloric, utili- 
tarian, and gustatory standards. Other factors being equal, the strategy involving the least amount of invested effort for the greatest return will be implemented. Over time, competitive pressures select for decisions and behaviors which are adaptive, that is, which optimize the decision makers' chances of survival and reproduction. The evolution of an optimal subsistence strategy is thus seen to result from the long-term accumulation and integration of experience through cultural means.

In keeping with more general cultural ecological theory, optimal foraging models relate cultural adaptedness to exchanges of energy, matter, and information between and within the social and physical environments (Flannery 1972). While energy (in calories), and to a lesser extent matter, are the currencies traditionally evaluated in cost-benefit analysis (Winterhalder 1981), the primacy of information exchange has been stressed in both synchronic and diachronic perspectives. Adequate information is recognized as prerequisite to decision making at a given moment in time. As Keene has noted, "The ability of a population to deal with environmental variability is largely a function of its ability to collect, process, and store information regarding this variability" (1981:192). Further, it has been argued that cultural integration and maintenance of information through time provides the material upon which selective processes act. In this diachronic case, "Information passed from generation to generation by culture provides much of the strategic framework within which specific choices and options are exercised by individuals or groups of human foragers" (Winterhalder 1981:17). In spite of this primary role, information acquisition typically has been held constant in optimal foraging models in the form of the all-knowing, computationally perfect, rational "decision maker" in order to elucidate the effects of changes in energy flow (Moore 1981).

The simplifying assumption of "omniscient rationality" circumvents the issue that information is a resource, and like all other resources, is not uniformly available in time and space, or even within a society (Moore 1983). Several authors have begun to explore the spatial and social parameters of information acquisition for hunter-gatherer groups (Moore 1981, 1983; Root 1983; Wobst 1974, 1976, 1977). The present paper initiates a similar concern for the cultural mechanisms of information transfer through time.

\section{Information Processing in Hunter-Gatherer Subsistence}

Accepting the basic validity of the model that hunter-gatherer subsistence practices result from conscious decision making, the present study is concerned with modeling the antecedent information-processing mechanisms which play a key role in long-term adaptive success. It is sug- 
gested here that the attained state of knowledge on which a decision is based is the result of the processes of data collection, analysis, and transmission. In terms of hunter-gatherer subsistence, data collection signifies both the direct monitoring of resource variability and the indirect acquisition of that knowledge through another source; analysis consists of the assessment of collected information for relevancy according to a reference set of culturally (technologically, socially, and ideologically) conditioned alternative reactions; transmission involves both the codification of data into transmittable form and its conveyance across time and space to the involved decision makers. In the abstract case involving temporal variability, data concerning a given environmental perturbation at Time $n$ is collected, synthesized, and assessed by the decision maker, the decision rule is implemented, and the form of the decision is selected. The outcome (success/failure) of the decision will then feed into the body of stored knowledge for future reference. This modified reference set will later be used to determine appropriate procedures for monitoring and analysis concerning a similar perturbation at Time $n+1$ (Fig. 1).

Laughlin and Brady (1978) have argued that the transmission through time of a body of reference knowledge is the aspect of information processing most critical in long-term survival. Without this cumulative storage of information, a process which they term "feed forward," "recurrent deprivation in a particular environment would appear as a discontinuous set of disasters, each calling for novel resolutions to escalated levels of environmental noxity" (1978:231). The feed-forward process functions on all time scales by providing cognition of the recurrent nature of the environmental perturbation, its potential effects, and the range of appropriate alternatives for behavior.

The specific cultural mechanisms involved in the feed-forward process are constrained by the time span over which they must operate. In the short term, subsistence involves adaptation to resource variability on the scale of expected, cyclical seasonal fluctuations or stochastic processes recurring within the lifetime of an individual. The means available for processing short-term information are embedded in the social mechanisms for the organization and distribution of group members. Resource variability, density, and distribution are monitored by individual observation, encoded orally, and disseminated verbally from one group member to the next or between group members through kin or ritual ties. The set of reference data for analysis, containing the various outcomes of implemented decisions or strategies, is contained in the living memory of individuals and thereby maintained within the group.

In the longer term, survival involves readjustments to the infrequent and perhaps catastrophic events recurring over a time scale greater than a single human generation. The monitoring of major fluctuations in re- 


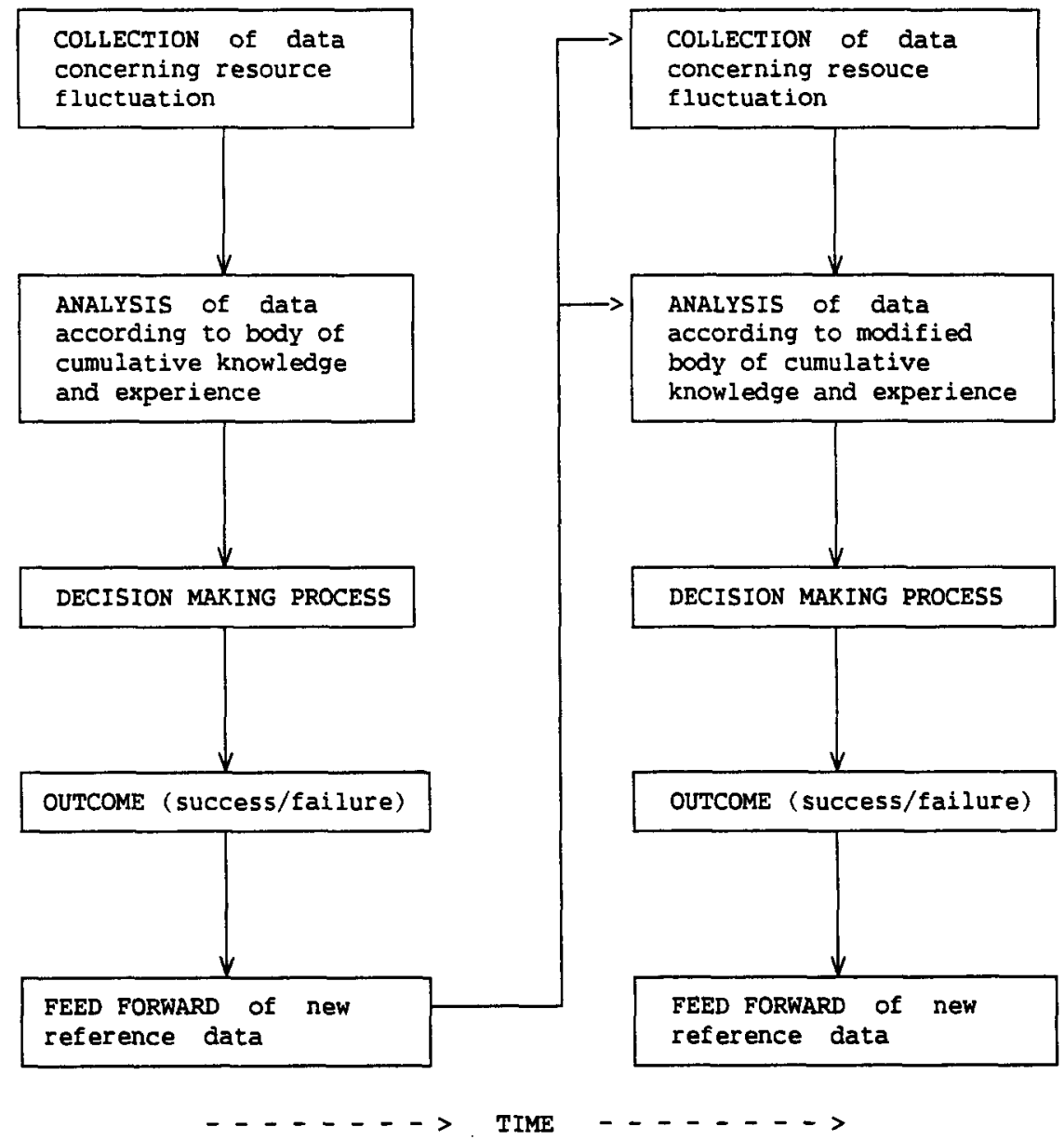

FIG. 1. Information processes surrounding decision making. At Time $n$, information concerning resource variability and alternative strategies is collected and analyzed prior to making a decision on which subsistence tactics to pursue. The outcome of that decision is evaluated and fed forward as part of the body of reference knowledge available at Time $n+1$.

source availability and the communication between concerned groups may well involve the same set of social mechanisms as in the short term. The set of reference data by which these processes are carried out, however, can no longer consist solely of the personal experiences and individual memories of group members, since the interval of elapsed time 
between perturbations of this magnitude may be longer than the span of an individual's lifetime. The retention of cumulative knowledge therefore implies the existence of some other means for the storage of information from one occurrence to the next and the retrieval of necessary reference data in crisis situations.

One time-sensitive mechanism potentially utilized by preliterate peoples for the transmission of crucial information across different spans of time is that of oral tradition. Oral tradition can be defincd as "oral testimony transmitted verbally from one generation to the next or more" (Vansina 1971:444), through the media of folk tales, songs, histories, and mythologies, as well as prescribed ritual chants, activities, and performances. A key characteristic of oral tradition as used here is that it occurs within a structured social context which delimits the means appropriate for the perpetuation of the given body of knowledge.

Two social contexts can be contrasted in this respect. Secular oral tradition, such as folktales, songs, and histories, depends on repetition for its perpetuation. The telling and retelling of an incident keeps it alive within the group. Unless specific controls to the contrary are in effect, however, individual error, elaboration, and/or creativity in the retelling will in the long run produce "noise" or distortion of information leading to a loss of accuracy.

An alternative means of ensuring the continuity of information transfer is through sanctification or the incorporation of information into a body of sanctified ritual action. Religious ritual comprises those prescribed performances and formal actions manifestly directed toward the involvement of supernatural agencies in the affairs of the actors (Rappaport 1979:28). Two features of ritual distinguish this medium as a context for information processing (Rappaport 1971). First, it must be performed to be effective, a measure which ensures repetition; second, its efficacy in securing supernatural assistance depends on the correctness of its production, a constraint which promotes accuracy in transmission. Ritual contexts therefore contribute to both the retention of knowledge as well as the accuracy of that knowledge. A middle ground may be argued for mythology. Origin or creation myths are derived from or treat subjects of a sanctified nature but they lack the performative necessity of ritual per se.

If we assume that greater accuracy is guaranteed by ritual recounting, it might be expected that most information relating to subsistence (and thus to survival) would be stored in this medium as opposed to the more variable secular oral tradition. There are several other factors, however, which affect the suitability of a medium for the storage of information. The first of these is social cost. Ritual action is generally an expensive proposition in comparison with the telling of folk tales or histories. Ritual 
performance may entail a number of restrictions on activities, tabus on foods, requisite offerings, and the like, which can be afforded by the community only at infrequent intervals.

A related determining factor is the accessibility of the encoded information through time and across space. If oral traditions are not uniformly available throughout the year, the timing of the performance of an oral tradition with respect to that of critical resource lows may determine its effectiveness as a survival manual. Rituals which follow a fixed schedule are potentially unresponsive to crisis situations; conversely, noncalendrical rituals may be initiated by factors keyed to increased levels of subsistence stress.

Similarly, the ease with which a medium is shared or transmitted over space affects that medium's ability to communicate crucial information to interdependent populations. While ritual requires the participation of group members, the details of ritual may be lost across group boundaries, thereby limiting the communicatory capacity of ritual at an intergroup level. As a result of increased social cost, infrequent or fixed occurrence and limited spatial distribution of ritual action, information contained in ritual is potentially less accessible than that encoded and transmitted by secular means.

The apparent balance between accuracy of transmission and accessibility of encoded information generates the following expectations for the use of oral tradition as a medium for information storage. First, the total range of oral tradition may potentially be used by a group as a means for the storage of relevant reference data concerning subsistence practices and survival. Second, the greater the interval of elapsed time between instances of a given fluctuation in subsistence resources, the greater the likelihood that this information will be transmitted through sanctified, as opposed to secular, forms of oral tradition. Third, the greater the magnitude of the fluctuation, the more likely it is that the importance of information concerning such an event will offset the social cost of its transmission such that the relevant data will be sanctified for storage.

In summary, the model can be stated as follows:

(1) Hunter-gatherer subsistence practices, as a form of economic behavior, can be modeled as the product of rational decision making between alternative choices.

(2) Decision making is based on an attained level of knowledge concerning these choices and therefore is predicated on mechanisms for processing information concerning resource variability, alternative strategies, and expected results of the strategies.

(3) Procedures for monitoring and assessing resource variability are embedded in the social mechanisms governing group mobility and distribution, and are carried out according to the survival experience of the group. The transmission of this body of accumulated experience is therefore crucial to group survival. 
(4) One mechanism potentially utilized to feed adaptive information forward in time is through its incorporation in oral tradition.

(5) Oral tradition transmits information concerning environmental fluctuations of different magnitude and periodicity according to the degree of accuracy and social cost of transmission as determined by the social context of the specific oral medium.

(6) Both secular and sanctified (ritual) forms of oral tradition may be utilized to transmit subsistence information; the use of sanctified forms over secular, however, will be expected to increase with the greater periodicity and magnitude of fluctuations in the subsistence resources.

\section{Evaluating the Model: The Ethnographic Case}

In evaluating the degree of fit between the proposed model and actual hunter-gatherer subsistence practices, the present paper focuses on the Tareumiut and Nunamiut Eskimos of northwest Alaska as a case study. The survival value of oral tradition in the long-term adaptive success of these groups was approached through the following questions:

(1) What is the nature of the subsistence resource base of these hunter-gatherers in terms of the amplitude and frequency of fluctuations in productivity?

(2) At what amplitude and periodicity do environmental perturbations necessitate economic restructuring on the part of these groups?

(3) What alternative subsistence strategies are available to the specified populations for coping with environmental lows of a given amplitude and periodicity? What cultural mechanisms facilitate the implementation of those strategies?

(4) How do the different media contained within the larger body of oral tradition differentially transmit to the members of the cultural system information concerning crisis situations of different scalcs? What correlations can be discerned between the specific oral medium as characterized by its contextually derived means of information storage and retrieval and (a) the nature of the economic crisis situation, and (b) the appropriate response to mediate the situation?

The Tareumiut and the Nunamiut provide an appropriate data base against which to pose the preceding questions for several reasons. First, these groups represent social systems adapted to an environment characterized by large-amplitude fluctuations in climate (Cropper 1982) and faunal resources (Ito 1980). If oral tradition serves to mediate subsistence crises, then its survival value should be apparent in this situation of extreme variability. Second, there is a fairly extensive historic and ethnographic record covering both the subsistence practices and the oral traditions of these groups. In addition, the subsistence practices as outlined in the literature suggest a primary dependency by each group on a single faunal species, and it is admittedly much easier to outline the variability of a single resource than the variability of multiple fluctuating resources. Finally, a large body of ecological data exists for these faunal species. from which the variability in these resources can be characterized. The example of the Tareumiut and the Nunamiut, while suggestive of the pos- 
sible role of oral tradition among other hunter-gatherer groups, is, of course, case-specific and does not necessarily represent a universal hunter-gatherer survival strategy. Clearly, cross-cultural comparison across a range of environmental contexts is necessary before any conclusive statement on the role of oral tradition in mediating subsistence crises is justified.

\section{THE TAREUMIUT AND NUNAMIUT OF NORTHWEST ALASKA}

The north slope of Alaska, extending northward from the Brooks Range to the Arctic Ocean, provided the distinctive ecological settings utilized by two indigenous groups, the Tareumiut and the Nunamiut. Traditionally, these groups occupied contiguous zones along the coast and in adjacent interior regions, respectively (Fig. 2). In the mid-1800s, the coast between Point Hope and Point Barrow was divided among the territories of five stable Tareumiut communities and several temporary settlements (Fig. 3). Inland, five regional groups have been delimited for the Nunamiut, associated with territories along major river drainages (Burch 1981; Gubser 1965; Spencer 1959).

The terms tareumiut and nunamiut reflect the indigenous distinction between the complementary resource zones of the coastal and inland habitats (Larsen and Rainey 1948; Spencer 1959). The Tareumiut, or

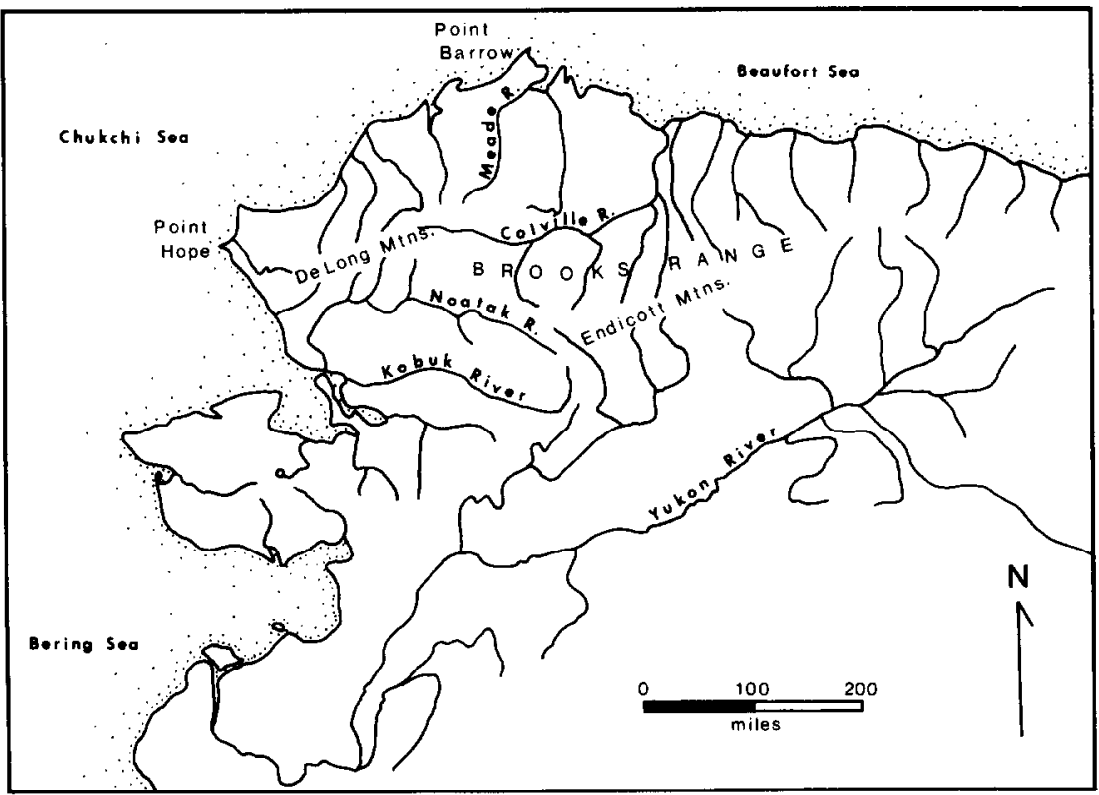

Fig. 2. Northwest Alaska. 


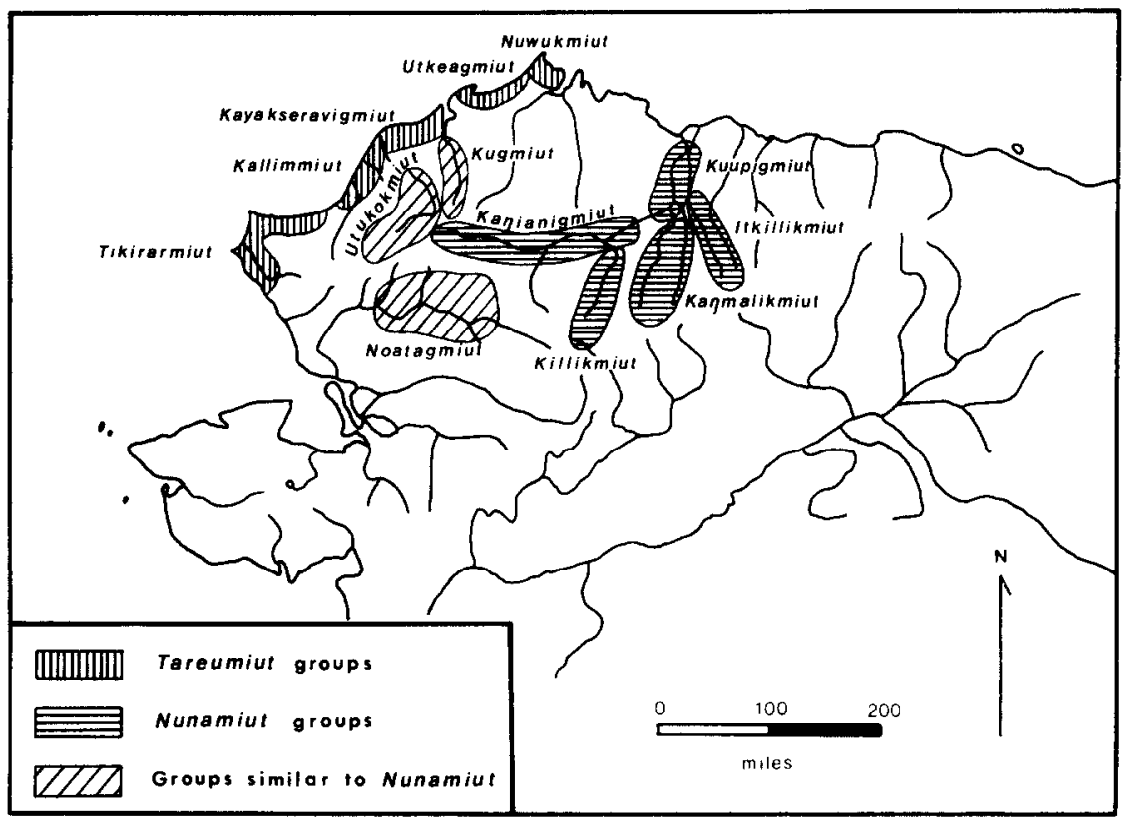

FIG. 3. Regional groups in Northwest Alaska ca. 1850.

"people of the sea," practiced a subsistence economy centered on sea mammal hunting with an emphasis on whaling. The localized abundance of marine resources enabled a demographic arrangement of relatively permanent village settlements along the coast. In contrast, the Nunamiut or "inland people," with their primary orientation toward the hunting of migratory caribou, ranged more widely over the tundra and foothills north of the Brooks Range.

The dual economy of land and sea characterized the traditional hunters of northwest Alaska. Since the 1850s, the impact of Euroamerican contact on these groups has been deep and irreversible. Foreign diseases decimated indigenous populations and altered settlement distribution. Firearms and wage labor have disrupted the subsistence cconomy and ecological balance, while missionaries have challenged the native belief system. In the reconstruction of traditional lifeways, this study has drawn extensively from historical accounts (Rasmussen 1927; Porter 1893), early ethnographics (Murdoch 1886, 1892; Simpson 1875; Stefansson 1919, 1922), native memories (Okakok 1981), and more recent studies of surviving remnant populations practicing a vanishing way of life (Binford 1978; Burch 1981; Gubser 1965; Lowenstein 1981; Milan 1964; Nelson 1969; Ostermann and Holtved 1952; Rainey 1947; Spencer 1959; Van Stone 1962). 
The separation of coastal and inland habitats, although not a strict dichotomy in actual practice (Burch 1981), was maintained to a large extent by their distinctive subsistence resources and by the skills and knowledge required for the efficient utilization of those resources. Cross-cutting these ecological differences, however, were shared subsistence strategies, principally the utilization of a broad range of resources in the course of a seasonal round while concentrating on one primary resource (Burch 1981).

Economic life in the coastal villages centered on the baleen or bowhead whale. From March through May, nearly every member of the community was involved in either the hunting of whales or the processing of whale products. Traditionally, whales were hunted by individual crews, who established whaling camps along the edge of the shore-fast ice and waited for the migrating whales to pass north near the shore. When a whale was sighted, the skin whaling boats were launched and the whale was attacked with harpoons and lances. After the whale had been secured and pulled ashore, the men returned to the ice edge. The butchering and storage of the meat in ice cellars was carried out by the wives and children of the crew.

Following the intensive whaling season, the coastal villages broke up for the summer. Individual families traveled inland along the rivers to hunt caribou or settle at fishing camps, while others remained on the coast for the walrus season of mid-July. By late summer, there was a general dispersion of population inland as groups headed for prearranged meeting places to trade with Nunamiut partners. In early fall, the population reassembled in the coastal villages for the fall whaling season, as the herds straggled back southward at this time. Fall whaling, however, was an opportunistic operation of relatively minor productivity. Similarly, the major subsistence activities of the late fall and winter (sealing and tomcod fishing) were unable to meet minimum food demands (Foote and Williamson 1966:1071; Shcchan 1985:135-136; cf. Burch 1981), and the population primarily supported itself through these seasons on stored food (Spencer 1959:141).

The seasonal round of the Nunamiut was marked by greater diversity than that of the Tareumiut. Like the Tareumiut, however, the Nunamiut concentrated on a single resource, the arctic caribou, and this dependency dictated certain constraints on a group's movements. As a rule, family groups were scattered throughout the interior along the watercourses of their home territories. In the spring, however, the population began to aggregate near the mountain passes in preparation for the caribou drive. For this spring hunt, each hunting crew constructed a corral or kangigak, consisting of two concentric circles of branches or vertical poles interset with snares. A run constructed of converging lines of posts 
led to the corral entrance, often across a distance of several miles. Once the caribou were driven into the impound, they were dispatched with arrows or spears. The carcasses were then skinned and butchered, and the meat prepared for drying and caching by the women. The men continued to scout out other herds or pick off stragglers. An alternative to the corral was the river or lake drive, in which the herd was attacked by hunters in kayaks as the animals attempted to ford the body of water.

After the spring hunt, the larger group separated into individual families which followed a nomadic course until winter. Most of these travelled at least as far as the coastal trading stations by late summer. Early fall saw a return to the foothills for sheep hunting, fishing, and berry picking, or a more direct trip to home territory, pausing to hunt and fish along the way. Winter months were generally spent at the family's fishing stations in the home territory, with individual excursions after caribou if available.

While both the Tareumiut and Nunamiut hunted a great variety of animals successfully, they both primarily depended on the only animal in their respective regions which could be taken in quantity, i.e., the bowhead whale and the arctic caribou, respectively. The degree of dependency on that single resource is measurable from the percentage of total annual intake which it provided. Traditionally, stored whale products constituted at least $50 \%$ of the winter food supply of the Tareumiut (Marquette and Bockstoce 1980:50; Sheehan 1985:131-136), although higher levels were utilized when available. Reconstructions of seasonal diet for inland groups along the Upper Noatak River in the early historic period (ca. 1850) indicate that caribou supplied $90 \%$ of the group's winter caloric needs, and $70 \%$ of their summer intake (Foote and Williamson 1966; Hughes 1974:588).

The primacy of the major resource in the diet was such that the failure of that resource could not be adequately mediated by reliance on secondary faunal resources. An unsuccessful whaling season threatened limited rations for the winter or starvation for a Tareumiut community (Spencer 1959:142). Similarly, if the caribou failed to appear in sufficient numbers, Nunamiut groups were faced with emigration or starvation (Amsden 1977; Gubser 1965). While isolated families might survive by exploiting secondary resources, these faunal elements were not sufficient to enable a society to exist in either region (Gubser 1965; Sheehan 1985).

For both the coastal and interior groups, the failure of the primary resource constituted a crisis situation. The scale and frequency of subsistence crises can accordingly be approached from the availability of the primary species relative to subsistence requirements. The following sections explore those factors which determine the abundance and accessibility of the arctic caribou and bowhead whale as subsistence resources, 
and present an operational model of the temporal and spatial variability of these key species relevant to traditional hunters.

\section{VARIABILITY IN PRIMARY SUBSISTENCE RESOURCES}

\section{The Arctic Caribou as a Subsistence Resource}

The productive potential of the arctic caribou (Rangifer tarandus grantii Mills.) as a subsistence resource for traditional hunting groups of interior northwest Alaska is a combination of both a relatively large body size and a high degree of seasonal aggregation (Burch 1972; Murie 1935:14-15; Skoog 1968:13). The actual availability of caribou as a resource, however, is quite variable and depends on (1) shifts in herd distribution through time, as well as (2) fluctuations in the overall size of the caribou population.

The caribou of Alaska and adjacent portions of Canada have been divided into six separate subpopulations or caribou regions. A given subpopulation is defined on the basis of a distinct calving ground or center of habitation which serves as the focal point for the spring migration, population build-up, and ultimate dispersal (Skoog 1968:202). Each subpopulation generally comprises a single herd which ranges within the bounds of its regional territory; little movement of animals between subpopulations or regions has been recorded. The inference is that each region defines the geographical limits within which herd distribution must be monitored while the subpopulation constitutes the biological unit which experiences fluctuations in overall herd size.

Shifts in herd distribution through time. The caribou of the Nunamiut study area constitute the northwest Alaska caribou subpopulation (Skoog's Region III). Seasonal movements by this population follow a generally north-south migratory path (Hemming 1971; Rausch 1951:187-188; Skoog 1968). The herd winters in the more protected areas of spruce-lichen woodland south of the Brooks Range and Endicott Mountains. Beginning in early spring, the herd moves northward through the Anaktuvuk Pass region to the tundra of the arctic coastal plain, where it remains throughout the summer months. With the onset of the freezeup in October, the entire herd returns south through the passes.

Within the general annual pattern, the caribou migration has been characterized as highly variable, both in volume and locus of concentration (Burch 1972:352; Skoog 1968:116). The apparent lack of predictability is typified by Murie's (1935:43) comments on the migration at Anaktuvuk pass:

One season the animals may come through in great numbers, massed in a good sized band, a striking procession. . . . Another season their passing may be almost 
unnoticed, as they dribble through in such small bands as to leave the impression that there are few caribou left in the country.

In contrast to the above situation, ethnographic accounts note that the corrals for caribou drives were used year after year (Rausch 1951:192) and were annually rebuilt in preparation for the spring drive (Spencer 1959:135). These and similar statements argue that a degree of predictability in herd distribution does exist on some time scale underlying the apparently erratic movements of the migrating herds.

Precedent and continued availability of suitable range have been identified as the primary factors controlling the interannual variability in the path of the migration (Baker 1978; Murie 1935; Skoog 1968). The adaptive advantage of migration determines that an animal will migrate when the suitability of the present habitat for reproductive success is less than that of the habitat to which the animal migrates, where the energy cost of the move is subtracted from the relative advantage of the new habitat (Baker 1978:36-43).

The return to a familiar range reduces search time and the risk of failure in locating a suitable habitat; accordingly, a familiar range will be reutilized consistently as long as it is advantageous to the herd. If the advantage lessens (e.g., through increased predation or environmental degradation) and falls below a certain threshold, then migration to a new area becomes advantageous (Baker 1978:44-52). Regular migration may then be established to the new area, depending on its suitability. This pattern of shifting habitat use has been documented for the barren-ground caribou of the Canadian tundra (Baker 1978:170-171; Kelsall 1968) and may be applied to the caribou of northwest Alaska as well.

The periodicity of habitat shifts is largely conditioned by the continued availability of suitable range. The major constituents of the caribou diet are lichens (Cetraria cucullata, Cladonia belliflora, and C. sylvatica), graminoid species, primarily cottongrass (Eriophorum vaginatum) and wet prairie sedges (Carex spp.), and deciduous shrubs, including willow (Salix pulchra) and dwarf birch (Betula nana) (Murie 1935:36-38; Skoog 1968:136-148; White and Trudell 1980). Plant species critical during migration (cottongrass and lichens) are especially vulnerable to overgrazing and trampling (Inglis 1975; Klein and White 1978:34; Moser et al. 1979). Under fairly high population densities (4.5 animals per square mile), a herd can effectively overgraze and destroy a lichen range after only 2 consecutive years (Inglis 1975). With more normal population densities of 1.0 to 1.5 caribou per square mile (Skoog 1968:650), the projected range use is on the order of 10 to 15 years before overgrazing occurs. Once depleted, a lichen mat requires between 20 and 50 years to return to a robust condition which will again support a caribou population (Moser et al. 1979; Palmer and Rouse 1945; Pegau 1968). 
TABLE 1

Summary of Historical Information on Caribou Herd Distribution

\begin{tabular}{|c|c|c|c|}
\hline Date & Location & Number present & Source \\
\hline 1837 & $\begin{array}{l}\text { Coastal plain E. of } \\
\text { Point Barrow }\end{array}$ & Large numbers & Skoog 1968 \\
\hline $\begin{array}{r}1830 \mathrm{~s}- \\
1870 \mathrm{~s}\end{array}$ & Seward Peninsula and Yukon & Large numbers & Skoog 1968 \\
\hline 1883 & Meade River & Large numbers & Skoog 1968 \\
\hline $1880 \mathrm{~s}$ & $\begin{array}{l}\text { Arctic slope E. of } \\
\text { Cape Lisbourne }\end{array}$ & Numerous & Skoog 1968 \\
\hline $1880 \mathrm{~s}$ & $\begin{array}{l}\text { Along Kobuk River and } \\
\text { Upper Koyukuk River }\end{array}$ & Numerous & Skoog 1968 \\
\hline 1884 & Kobuk and Noatak Rivers & Numerous & Murie 1935 \\
\hline $\begin{array}{l}1898 \\
\text { early }\end{array}$ & $\begin{array}{l}\text { Kobuk and Noatak Rivers } \\
\text { Along Colville River. }\end{array}$ & Empty of caribou & Murie 1935 \\
\hline $1900 \mathrm{~s}$ & $\begin{array}{l}\text { Along Colville KIver, } \\
\text { DeLong and Endicott Mts. }\end{array}$ & Center of abundance & Skoog 1968 \\
\hline $1900-1901$ & W. of Colville and Chipp Rivers & Plentiful & Murie 1935 \\
\hline $1901-1905$ & E. of Colville River & Plentiful & Murie 1935 \\
\hline $1900 \mathrm{~s}$ & N. slope of DeLong Mts. & More abundant & Murie 1935 \\
\hline 1911 & Colville River headwaters & Always abundant & Murie 1935 \\
\hline 1920 & $\begin{array}{l}\text { E. of Lake Chandalar, } \\
\text { Wiseman Village area }\end{array}$ & Population shift & Skoog 1968 \\
\hline 1925 & Head of Utokok River & Common & Skoog 1968 \\
\hline $1924-1925$ & Colville River watershed & Common & Murie 1935 \\
\hline $1920 \mathrm{~s}$ & $\begin{array}{l}\text { DeLong and Endicott Mts., } \\
\text { N. of Upper Colville River }\end{array}$ & Abundant & Skoog 1968 \\
\hline $1920 \mathrm{~s}$ & Coastal plain & None & Skoog 1968 \\
\hline $1920 s$ & Kobuk River drainage & None & Skoog 1968 \\
\hline 1935 & $\begin{array}{l}\text { N. of Seward Peninsula } \\
\text { on Bering Coast }\end{array}$ & Present again & Skoog 1968 \\
\hline $\begin{array}{l}\text { late } \\
\qquad 1940 \mathrm{~s}\end{array}$ & Along Kobuk River & $\begin{array}{l}\text { Major portions of } \\
\text { the population }\end{array}$ & Skoog 1968 \\
\hline
\end{tabular}

The combined factors of familiarity with a range and habitat suitability generate a pattern of interannual variability in the location of the caribou herd migration consisting of a period of regular use of a given range, followed by a period of avoidance, and subsequent renewed use. Both the period of range use and recovery is contingent on the density of the caribou herd. Under average population densities, a given range site could experience 10 to 15 years of regular use, followed by a 20-year minimum period of recovery.

The proposed cycle of use and abandonment of a given range by the northwest Alaskan herd finds support in historical records of caribou distribution within the region (Table 1). Major shifts in caribou distribution through time as delineated by Skoog (1968) and Murie (1935) show a variable periodicity in herd relocation ranging between 10 and 40 years. The 
region between the Kobuk and Noatak rivers, for example, was grazed by caribou in the years 1884,1925 , and the late 1940 s, but was noted as empty of caribou at temporal points in between. The centrally located Colville River valley was reoccupied more frequently; historic records indicate numerous herds in this area in 1900, 1911, and 1925.

Fluctuations in herd size. The problem of caribou availability posed by shifting range use is compounded by fluctuations in total herd size. Reconstructions of caribou population dynamics through time have been generated from three bodies of data: (1) specific historical data on the northwest Alaskan herd; (2) population figures for related arctic herd ungulates (e.g., domestic reindeer $R$. tarandus tarandus L.); and (3) the simulation of ecological parameters controlling herd increase and decline. These three approaches concur in characterizing caribou herd size as strongly cyclical in nature, with a period of 60 to 100 years between peaks.

Historical population estimates for the northwest Alaska herd are based on the relationship between overall density of caribou per square mile and their distribution within the regional territory (Skoog 1968:648650 ; Burch 1972:356). A comparison of historically documented herd distributions with recent maps of herd distribution for known population densities has generated a series of population estimates which reconstruct fluctuations in overall herd size through time (Aigner 1982; Burch 1972; Lent 1966; Skoog 1968). Early accounts indicate that the caribou herd was at a population peak during the middle $1800 \mathrm{~s}$, with an estimated population size of several hundred thousand. Between 1850 and 1860 , the herd began to decline and reached a low of several thousand by 1900 . After a period of low density which continued through the 1940s, herd size began to rise rapidly to a new peak in 1960 . Since that time, herd size has again begun to drop off. Reliable estimates for 1970 indicate a population of 242,000 (Burch 1972:356). By 1975 the herd had declined to 100,000 and by 1976 to 75,000 (Davis et al., in press, quoted in Mitchell and Reeves 1980:721). The downward trend was reversed through a management policy of highly restricted exploitation, allowing the herd to recover to a size of 140,000 by 1980 . These historical population estimates indicate that fluctuations in the size of the northwest Alaska herd approximate a sigmoidal function, with an amplitude characterized by a 95\% reduction from population maximum to minimum.

Several analysts have argued that the drastic fluctuations observed in the northwest Alaska herd represent a unique occurrence, resulting from specific historical factors. The introduction of fire-arms, overhunting to supply whaling crews (Gubser 1965:307; Lent 1966:483; cf. Bockstoce 1980), and the destruction of winter range by fur trappers' fires (Binford 1983:207) are cited as precipitating the decline of the caribou population in the late 1800 s. 
Other arctic herds, however, under very different conditions of exploitation, show similar strongly cyclical fluctuations in population size. In Alaska, the Nelchina caribou subpopulation and the St. Matthew Island reindeer herd demonstrate population growth curves essentially parallel to that reconstructed for the northwest Alaskan herd, with strong peaks in 1860 and 1960 (Hemming 1975). Similarly, the combined evidence from historical sources, hunting statistics, and direct census indicate that the caribou herd of western Greenland experienced population peaks in the 1740 s, 1850s, and 1960s, separated by periods of sharp (90\%) decline (Meldgaard 1983; Vibe 1967). The widespread occurrence, regular periodicity, and consistent amplitude of these population oscillations suggest that although historical factors may have contributed to the decline of a caribou herd, cyclical fluctuations in herd size are characteristic of the species and can be extrapolated into the prehistoric period.

Fluctuations in caribou population size can be reconstructed for the prehistoric period through identification of the ecological factors regulating population growth and decline, and extension of these factors into the past through independent means. The primary parameters controlling the dynamics of caribou populations are (1) range carrying capacity, and (2) winter kill (Klein and White 1978; Reimers 1982; Skoog 1968). Severe overgrazing of pasture following peak population densities has been identified as the major factor leading to reduced physical condition and sharp population decline in domestic reindeer herds (Klein 1968; Scheffer 1951). Winter weather conditions potentially limit arctic populations of caribou and reindeer without a preceding overgrazing of ranges (Klein and White 1978; Reimers 1982; Skoog 1968). Under conditions of high precipitation, the formation of ice crust over vegetation leads to starvation and increased mortality. Wolf predation has a secondary, density-dependent relationship to caribou population size which affects the steepness of the decline or recovery of the herd, but does not trigger oscillations (Klein and White 1978).

The carrying capacity of a given range is limited by factors governing the rate of range growth and recovery. Summer pasture, critical for fat accumulation and successful overwintering of caribou populations, consists primarily of perennial tundra species whose growth responds annually to temperature and moisture conditions. The growth and productivity of many of these species increases with total solar irradiance, and air and soil temperature (Bliss 1971:417; Kummerow et al. 1980; Miller et al. 1976; Tiezen 1973; Brown et al. 1980). The primary growth-limiting factors are low solar radiation and low temperatures, which co-vary with increased precipitation.

Winter range, in contrast, while crucial for caribou survival in lean periods, consists of the foliose lichen mat which demonstrates extremely slow growth even under favorable conditions of high moisture and mod- 
erate light (Ahmadjian 1967:90-91; Hale 1967:78; Pegau 1968). Due to slow growth response, variable climate conditions have little immediate impact on the available lichen biomass; in the long term, the lichen mat will display a lagged positive response to periods of greater precipitation.

A second factor limiting the reproductive success of caribou and reindeer populations is reduced availability of winter forage due to high precipitation levels. In western Greenland, "The reindeer managed well as long as the winter climate was cold and dry, in spite of poor vegetation; but the population was reduced as soon as the winter climate became humid, because then the vegetation was hidden under snow and ice" (Vibe 1967:165). Annual statistics recording the number of individuals hunted from this population between 1910 and 1950, show a strong negative relationship between the size of the herd and winter precipitation, supporting the claim that the decline of the herd was attributable to a period of wetter winters. In Norway, a single bad winter destroyed 23\% of the Svalbard reindeer population, sending the herd into a sharp decline (Reimers 1982).

Long-term trends in climate conditions affecting both range growth and winter mortality can be reconstructed for the northwest Alaska area using dendroclimatological data from arctic tree-line spruce stands. Temporally, growth patterns of arctic spruce contain an integrated climate signal; tree-ring widths respond to climatic conditions over a period greater than the growing season and are indicative of year-round average temperature and precipitation trends (Jacoby and Cook 1981). Spatially, these sequences reflect widespread meteorological phenomena; significant correlations between tree-ring sequences at separating distances of greater than $1000 \mathrm{~km}$ (Cropper 1982) justify the extrapolation of tree growth variability for a considerable distance from the stand site.

Several authors have examined specific climate-growth relationships for arctic tree-line species through a comparison of tree-ring widths with various climatic indices (Cropper 1982; Cropper and Fritts 1981; Garfinkel and Brubaker 1980; Jacoby and Cook 1981; Kay 1978). This response function analysis defines the correlations of radial growth with monthly temperature, precipitation, and/or pressure anomalies during and preceding the actual growing season using a multivariate regression procedure (Fritts et al. 1971). The predominant species from the Brooks Range, white and black spruce (Picea glauca and $P$. mariana), show a positive correlation with concurrent summer temperature, but a negative response to concurrent summer precipitation and preceding winter precipitation (Cropper and Fritts 1981; Garfinkel and Brubaker 1980). Cropper (1982) correlates differential tree growth in northwest Alaska with the relative persistence of large-scale pressure systems. Abovenormal tree growth reflects a strengthened Arctic high generating clear, 
dry air, and warm temperatures inland, while below-normal tree growth relates to a weakened Arctic high and the northern displacement of a Pacific maritime high responsible for cold, wet weather.

The success of the caribou population can be predicted from the response of Alaskan spruce to known temperature and precipitation regimes. Wider tree-ring widths reflect years with mild temperatures and dry conditions, optimal for the growth of arctic tundra species and range regeneration. The formation of narrow rings, in contrast, records conditions of high precipitation and low temperatures, indicative of years with reduced range growth, greater snow and ice coverage of available range, and a higher incidence of winter kill in caribou.

Tree-ring sequences from white and black spruce stands along the Noatak River drainage provide a record of climatic variability for the region north of the Brooks Range from 1800 through 1940 (Giddings 1941). The comparison of this growth record with the reconstructed curve of caribou population size for the historic period illustrates strong parallel responses to climatic fluctuations (Fig. 4). Above-normal tree-ring growth from 1830 until 1860 indicates a period of warmer and drier conditions, corresponding with the build-up and peak of caribou population. The period from 1870 to 1920 , in contrast, is marked by below-normal tree-ring growth and a sharp decline of the northwest Alaska caribou herd.

Additional tree-ring sequences based on drift wood from archaeological contexts within this region extend the climatic record back from the mid-1800s to AD 1550 (Fig. 5). These chronologies register long-term climate cycles consisting of periods of warmer, dryer conditions followed by colder and wetter conditions. A direct response on the part of the caribou population to such alternating climatic conditions argues that the

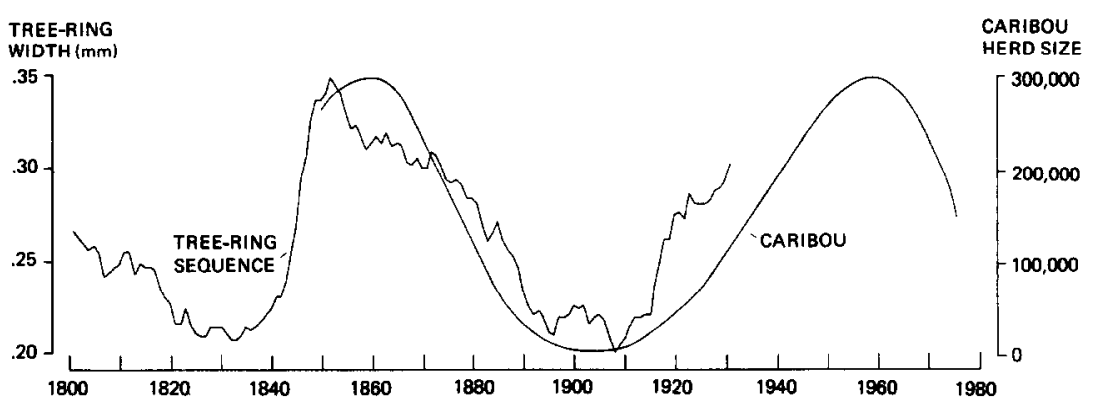

FIG. 4. Response of northwest Alaska caribou population to long-term climatic fluctuations. Variability in temperature and moisture regimes regulates patterns of tree-ring growth in arctic spruce (Picea glauca and $P$. mariana). Narrow rings reflect conditons of high precipitation and low temperatures; caribou population declines due to snow and ice cover over winter range. 

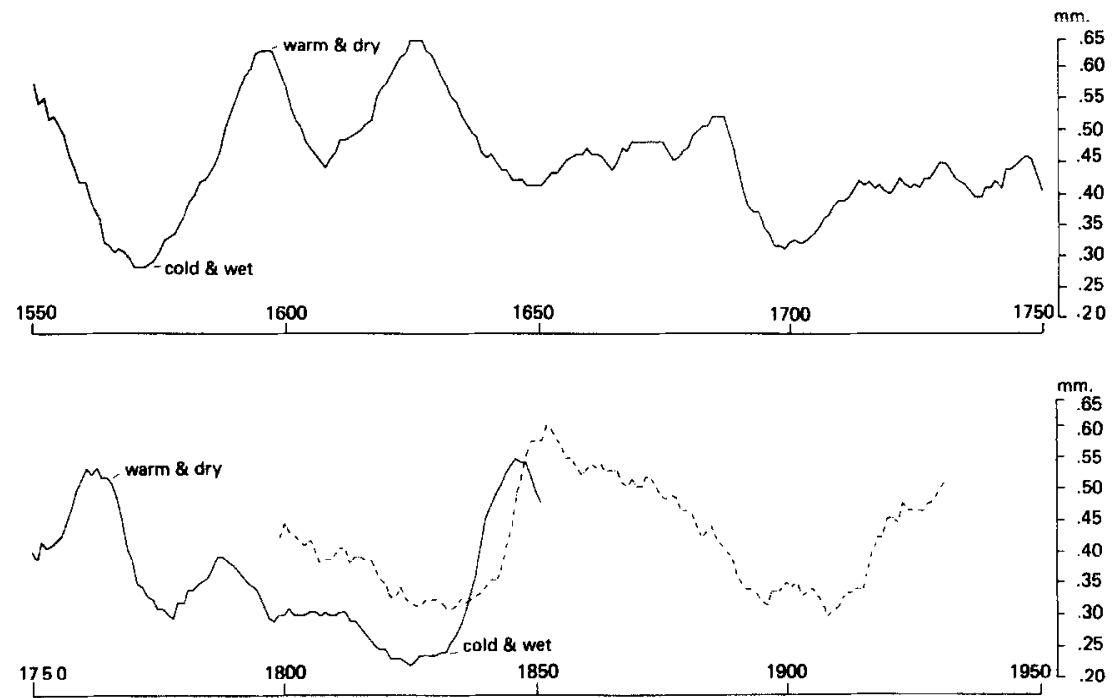

FIG. 5. Climate reconstruction from tree-ring chronologies, northwest Alaska, 1550-1950. —, Driftwood Series A; - •-, , Noatak.

availability of caribou as a subsistence resource can be characterized as strongly cyclical in nature, with a variable periodicity between 60 and 100 years.

In summary, caribou populations respond to two interrelated cycles which affect their availability as a subsistence resource. First, caribou demonstrate a short-term distributional cycle in local range use with a time span averaging 15 to 20 years. Second, caribou populations experience longer term cycles in absolute numbers, with a period of 60 to 100 years between peaks in population size.1,* The combined temporal and spatial effects of these cycles suggest that a hunting population dependent on caribou would face localized resource shortages at least once each generation, and an extended, regional subsistence crisis every three to five generations.

\section{The Bowhead Whale as a Subsistence Resource}

The baleen or bowhead whale (Balaena mysticetus) has been characterized as providing an abundant and highly productive resource base for the aboriginal coastal communities of northwest Alaska. During the prehistoric period, the bowhead whale population of the Arctic, Bering, and Chukchi Seas approached 18,000 individuals with little impact from indigenous whaling communities (Braham et al. 1980; Breiwick et al. 1981;

* See Notes section at end of paper for all footnotes. 
Mitchell and Reeves 1980). An "average" catch measured in at 30 feet (Maher and Wilimovsky 1963) and yielded an estimated 30,000 pounds of meat in addition to the 100 barrels (25,000 pounds) of oil and 1500 pounds of baleen reported by commercial whalers (Marquette and Bockstoce 1980).

The concentrated migratory movements of the bowhead whale contribute to the local abundance of this species (Mitchell and Reeves 1980:704). Whales, as mammals, are restricted in their seasonal movements to areas of open water where they can periodically surface to breathe. Both the path and the timing of migration are therefore constrained by the extent of open water in the sea ice (Carrol and Smithhisler 1980). In the spring, the Western Arctic population migrates from the Bering Sea north along the Alaskan coast to the calving area and summer feeding grounds of the Beaufort Sea. The route of the spring migration is confined to an intermittant formation of narrow cracks or leads of open water created between the shore-fast ice and sea ice by spring wind and thermal conditions. This lead system becomes increasingly narrower and closer to shore with the northward movement and reaches its point of greatest constriction at Point Barrow. The movement of the whales is constricted such that the entire migrating herd is funneled past, and in close proximity to, the coastal whaling communities of northwest Alaska (Braham et al. 1980). In the fall, the whale population returns south to the lower Bering Sea. The fall migration, in contrast to that of the spring, is not constrained by the narrow lead formations and the herd can spread out over the entire ice-free Arctic waterway. Indigenous whaling communities accordingly focused their collective efforts on the more concentrated spring migration, although fall whaling took place on an opportunistic basis.

While the bowhead population is locally abundant during spring migration, the actual availability of whales and the whalers' success depended on appropriate whaling conditions. From the perspective of the native whaler, those factors which affect the success of the annual hunt include the distance from shore to the open lead, the width of the lead, the length of time the lead remains open, the strength and direction of the wind, and the roughness of the water. These parameters are determined by weather patterns which may change daily or seasonally (Maher and Wilimovsky 1963).

The intervening effect of weather conditions in determining whaling success implies that the overall abundance of the bowhead is an inadequate measure of its local availability as a subsistence resource. The temporal variability of this species as a resource is accordingly modeled from historical measures of local procurement success.

Procurement success during the historic period. The present analyses 
of local procurement success utilize historical source material on shorebased catch of bowhead whales in the Bering, Chukchi, and Beaufort Seas, compiled by Marquette and Bockstoce (1980). In this context, "shore-based catch" or "shore-based operations" refers to the indigenous practice of launching the whale boat from the shore-fast ice after the whale has been sighted. These whaling activities are therefore distinct from the operations of ocean-going vessels of the American fleet. The historical data provide a detailed account of native whaling through annual statistics on the number of whales landed or struck but lost, as well as the number of active crews, for the major whaling sites along the Alaskan coast.

Three phases of shore-based whaling activity have been defined within the historic period (1850 to present):

(1) the aboriginal phase prior to contact with commercial whalers of the $1880 \mathrm{~s}$, during which the Alaskan Eskimos hunted bowheads with traditional harpoons and sealskin floats;

(2) the commercial phase spanning the end of the 19th and early 20th centuries, in which commercial whalers established whaling stations along the coast utilizing Eskimo crew members and traditional hunting practices with the exception of the introduction of shoulder and darting guns;

(3) the subsistence phase following the collapse of the commercial whaling industry in 1910 up to the present day, marked by a return to whaling as a subsistence activity but with the continued use of shoulder and darting guns (Marquette and Bockstoce (1980).

Within the Tareumiut region, the historical record is fairly complete between 1880 and 1977 for the indigenous communities of Barrow and Point Hope (Fig. 6). The annual success of these communities varied greatly, with catches fluctuating between 0 and 30.2 Over the longer term, periods of greater and lesser prosperity reflect the changing status of the whaling industry; however, the high degree of interannual variability cross-cuts all phases of shore-based whaling activities.

Three major sources of historically introduced variability potentially distort native whaling during the historical period as a model of prehistoric whaling success: (1) the changing role of whaling from a subsistence pursuit to a commercial enterprise; (2) the introduction of new technology; and (3) the extreme reduction of the whale stock.

The shift between subsistence and commercial whaling pursuits is reflected in the intensity of whaling effort. The number of crews actively engaged in whaling varied annually in response to the commercial value of whale products and the availability of alternative sources of income (Foote and Williamson 1966; Marquette and Bockstoce 1980). Annual whaling success between 1880 and 1977 , however, demonstrates only a weak response to the varying level of whaling effort. A low but significant correlation $(r=.3139)$ is observed between annual catch and active 


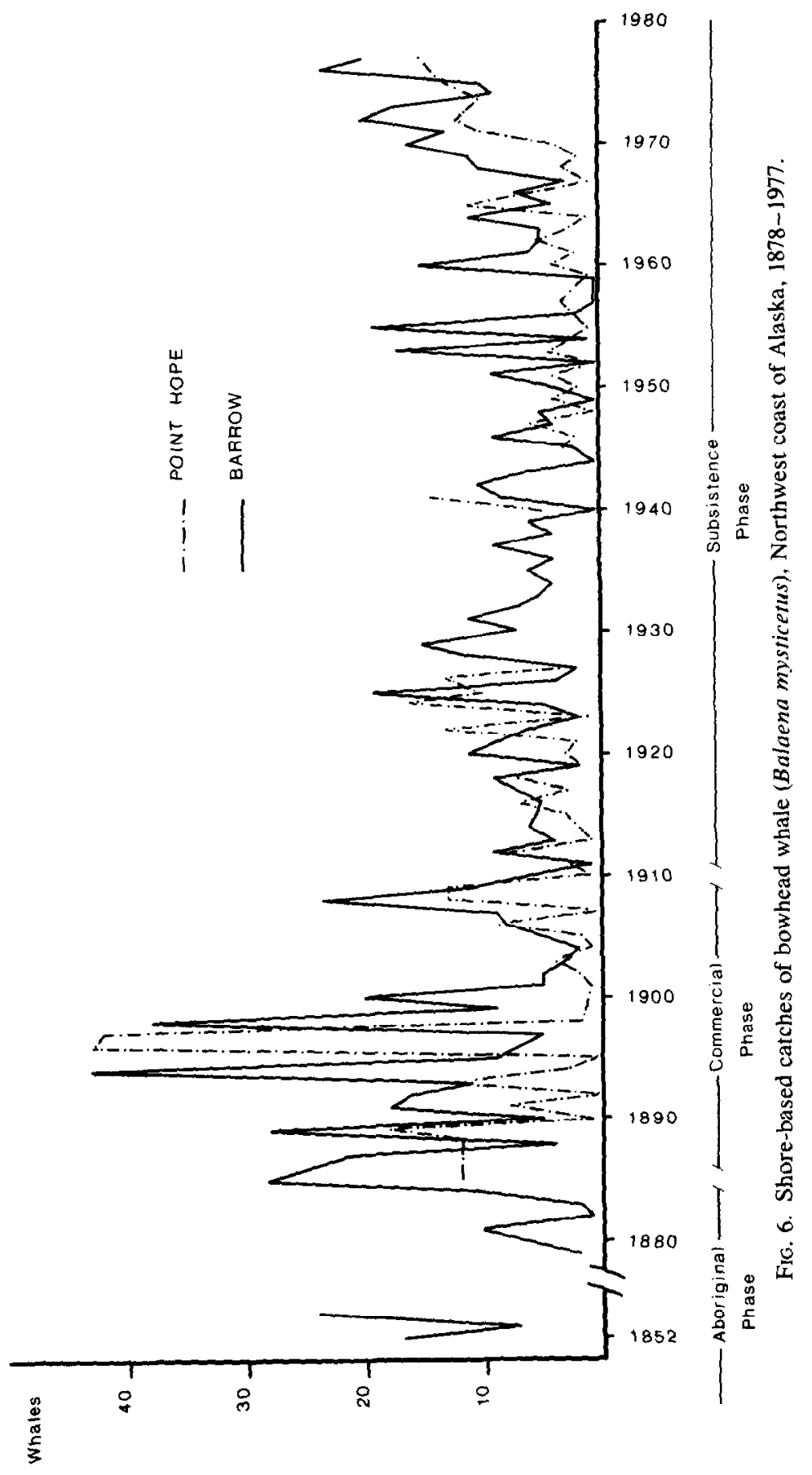


crews at Barrow, while at Point Hope the correlation between catch and crews is not significant.

Changing technology and hunting methods have altered whaling success in terms of the percentage of whales struck and landed. In the aboriginal period, native whalers utilized two weapons for attacking the bowhead whale: the harpoon with multiple attached floats and the lance. Floats exhausted the animal and enabled the hunter to track its movements until it was safe to approach and lance the vital organs. During the commercial phase, the harpoon and lance were replaced by the darting gun, which simultaneously embeds a harpoon line and float in the whale while discharging an explosive missile, and the shoulder gun, which fires an unattached bomb at the whale (Mitchell and Reeves 1980).

The addition of explosives to native technology unquestionably increased whale mortality over the preceding aboriginal phase. Since the commercial phase, however, this advantage has been reduced, in part, by the reliance on homemade bombs which frequently fail to explode (Mitchell and Reeves 1980). A more serious problem has been the replacement of the darting gun harpoon with shoulder guns. Although requiring less accuracy and skill, shoulder guns allow an injured whale to elude pursuit unimpeded by attached floats, and result in a greater number of struck but lost whales (Marquette 1977).

The overall reduction of the bowhead stock due to commercial whaling has potentially limited the availability of that species as a subsistence resource. Between 1850 and 1900, the American whaling fleet reduced the North Pacific bowhead population to less than a tenth of its pre-contact size of 18,000 (Breiwick et al. 1981). Recovery of the population has been slow, with a recent estimate of 2300 (Breiwick et al. 1981). Annual whale catches at Barrow and Point Hope show no significant correlation (at the .05 level) with the substantial changes in stock size between 1880 and the present. This finding supports the observation that, while regionally scarce, the bowhead remains locally abundant along the northwest coast of Alaska (Mitchell and Reeves 1980).

The impact of historically introduced changes in whaling effort, technology, and stock size on whaling success between 1880 and 1977 appears limited. Annual take shows only a weak relationship to the number of crews actively engaged in whaling. The addition of explosives to whaling technology has been balanced by the loss of traditional skills required for their effective use. Finally, the overall reduction and minor recovery of the whale stock have had no discernable effect on the local availability of the bowhead.

Weather and whaling success. Native whalers have identified weather and its effect on whaling conditions as the primary factor determining whaling success (Lowenstein 1981; Maher and Wilimovsky 1963; Mar- 
quette 1977; Nelson 1969; Ray 1885). Those conditions which contribute positively to successful whaling include a narrow, open lead formation, good visibility, and safety. Ideally, "the lead should be close to shore for easy access with whaling gear, and it should remain open and narrow so that the whales are forced to pass near the shore-fast ice" (Maher and Wilimovsky 1963). The opening of the lead requires an off-shore wind to separate the sea ice from the shore. A sea wind, in contrast, drives the pack-ice against the shore and closes the leads (Marquette 1977; Ray 1885; Saario and Kessel 1966:994). The observation and pursuit of whales is contingent on clear and calm conditions. Strong winds, rough water, and/or precipitation in the form of snow or fog limit visibility (Foote and Williamson 1966:1082; Maher and Wilimovsky 1963) and increase the risk of whaling boats at sea (Marquette 1977). Further, the safety of the whalers as well as their camp and equipment partially depends on water and air temperature. Low temperatures postpone the disintegration of the shore-fast ice and the time at which it becomes unsafe to continue whaling (Maher and Wilimovsky 1963).

The configuration of weather conditions identified by native whalers as adversely affecting whaling success (i.e., high precipitation and wind velocity, warm temperatures, and an on-shore wind) represent the early onset of maritime conditions under the influence of an Arctic high pressure system. A distinct maritime zone develops seasonally along the coast in response to spring snow melt. As inland temperatures rise, the temperature differential advects the warmer air seaward; the resulting pressure deficit causes an inland surface flow of air or sea breeze off the ice-covered ocean (Moritz 1977; Myer and Pitelka 1979). The movement of warmer air seaward creates higher temperatures over water and ice (Haugen and Brown 1980) and contributes to the break up of the sea ice (Barnett 1976; Rogers 1978). With the appearance of open water, the sea breeze becomes increasingly maritime in character, generating cloudy, moist, and windy conditions along the immediate coast (Allen and Weedfall 1966; Haugen and Brown 1980).

The relationship between spring weather conditions and whaling success was examined for the period from 1931 to 1977, the years for which both climatic and whaling records are available. The weather data consist of monthly average temperature, total precipitation, and mean sea level pressure values for the spring whaling season (March through June) recorded at the Barrow weather station (World Meteorological Organization 1971-1977; World Weather Records $1947 ; 1959 ; 1966 ; 1979)$. Several important meteorological factors, including wind velocity and direction, were not considered here due to insufficient data. The 1963 season was excluded from the analysis on the basis of extreme weather values. ${ }^{3}$ The weather records for the spring season were compared with annual catch, 
as the spring and fall seasonal catches are not consistently separated in the historic catch records. However, the spring catch comprises an estimated $80 \%$ of the annual catch (Maher and Wilimovsky 1963) and represents the major component of inter-annual variability.

The impact of spring weather on annual catch, given the historical sources of perturbation, was evaluated using a forward stepwise regression model. The spring weather measures constituted "free" variables to be potentially selected by the model, while the number of crews per season and the size of the whale stock were "fixed" in the equation. The effects of technology were assumed to be fairly constant across this period and were not included in the model.

The final regression model for Barrow includes four monthly weather variables in addition to the number of crews and stock size (Table 2). The addition of these weather variables accounts for $76 \%$ of the variability in annual catch at that station (as compared with the $25 \%$ explained by whaling effort and stock size) indicating that weather has a substantial effect on annual success. As predicted by native accounts, whale catch is negatively affected by March precipitation, June precipitation and March sea level pressure, and positively by June temperature. ${ }^{4}$ The explanatory value of the final regression equation is illustrated through the acceptably linear fit between actual catch and that predicted by the model (Fig. 7).

Spring weather constitutes a less successful indicator of whaling success at Point Hope, a factor which may be due to the use of weather values from the Barrow weather station, at a considerable distance up the coast. The final model for this community accounts for only $44 \%$ of the variability in annual catch; however, this constitutes a substantial increase over the $28 \%$ explained by whaling effort and stock size (Table 3 and Fig. 8). March precipitation is the single weather variable included, and has a strong negative effect on annual take.

The preceding analyses of whale catch at Barrow and Point Hope between 1931 and 1977 indicate that weather has a much stronger effect on the interannual variability in whaling success than do changes in whaling effort and stock size. Years of reduced catch are associated with high precipitation and high sea level pressure indicative of the early development of maritime conditions. Although these results are based on a limited subset of the historical data, they are in agreement with accounts of native whalers from both the early historic and recent periods.

Temporal variability in bowhead procurement. Interannual (shortterm) variability in whaling success was modeled on the basis of variability in local weather conditions between 1931 and 1977, using the previously developed regression equation. The effects of historical perturbations on catch were removed by assuming a constant (average) level of whaling effort and stock size across this period. Annual catches as predicted from spring weather are presented for Barrow in Fig. 9. 
TABLE 2

Regression Model for Factors Determining Whaling Success, Barrow, Alaska:

Forward Stepwise Regression of Catch on Weather Variables, Given Number of Crews, and Changes in Stock Size

\begin{tabular}{|c|c|c|c|c|c|}
\hline \multicolumn{3}{|c|}{ Analysis at Step 4 for Barrow Catch } & \multirow{2}{*}{$\begin{array}{l}N=25 \text { of } 46 \\
\text { Mean square }\end{array}$} & \multirow[b]{2}{*}{$f$ stat } & \multirow[b]{2}{*}{ Signif } \\
\hline Source & $d f$ & Sum of sqrs & & & \\
\hline Regres: & 6 & 651.03 & 108.50 & 9.4988 & .0001 \\
\hline Error & 18 & 205.61 & 11.423 & & \\
\hline Total & 24 & 856.64 & & & \\
\hline
\end{tabular}

Multiple $r=.87177 r^{2}=.75998 \mathrm{SE}=3.3798$

\begin{tabular}{lcccrr} 
Variable & Partial & Coefficient & SE & $t$ stat & Signif \\
\hline Constant & & 308.55 & 167.11 & 1.8464 & .0813 \\
Jun. temp & .58718 & 2.7935 & .90767 & 3.0776 & .0065 \\
Mar. prec & -.76746 & -34.008 & 6.6960 & -5.0789 & .0001 \\
Jun. prec & -.46553 & -5.9216 & 2.6535 & -2.2316 & .0386 \\
Mar. mslp & -.39906 & -.30204 & .16358 & -1.8464 & .0813 \\
Crews & .32078 & .12978 & $.90320-1$ & 1.4369 & .1679 \\
Stock & .45079 & $.54717-2$ & $.25538-2$ & 2.1426 & .0461
\end{tabular}

\begin{tabular}{lrl} 
Remaining & \multicolumn{1}{c}{ Partial } & Signif \\
\hline Mar. temp & -.10609 & .6656 \\
Apr. temp & -.04366 & .8591 \\
May temp & .35275 & .1385 \\
Apr. prec & -.00314 & .9898 \\
May prec & -.33964 & .1548 \\
Apr. mslp & -.08501 & .7293 \\
May mslp & .12286 & .6163 \\
Jun. mslp & .03411 & .8897
\end{tabular}

Regression of Barrow Catch Using Forward Selection

\begin{tabular}{ccccccrr} 
Step & $r^{2}$ & SE & No. Var & Variable & & Partial & Signif \\
\hline 0 & .25378 & 5.3904 & 2 & & In & & \\
1 & .57493 & 4.1641 & 3 & Mar. prec & In -.65603 & .0007 \\
2 & .66788 & 3.7717 & 4 & Jun. temp & In & .46761 & .0282 \\
3 & .71451 & 3.5877 & 5 & Jun. prec & In -.37472 & .0942 \\
4 & .75998 & 3.3798 & 6 & Mar. mslp & In -.39906 & .0813 \\
\hline
\end{tabular}

In the short-term, whaling success at Barrow is characterized as highly variable, with a run of good years followed by 1 or more years of low catches. Whale catch over this period approximates a normal distribution; however, the high standard deviation $(s=5.11)$ reflects the amplitude of the strong annual fluctuations. Scarce years, defined as catches greater than one standard deviation below the mean, occurred in 9 of 47 years, or roughly $20 \%$ of the time. No regular periodicity in the occurrence of bad years is observable in the data. The apparent absence of 


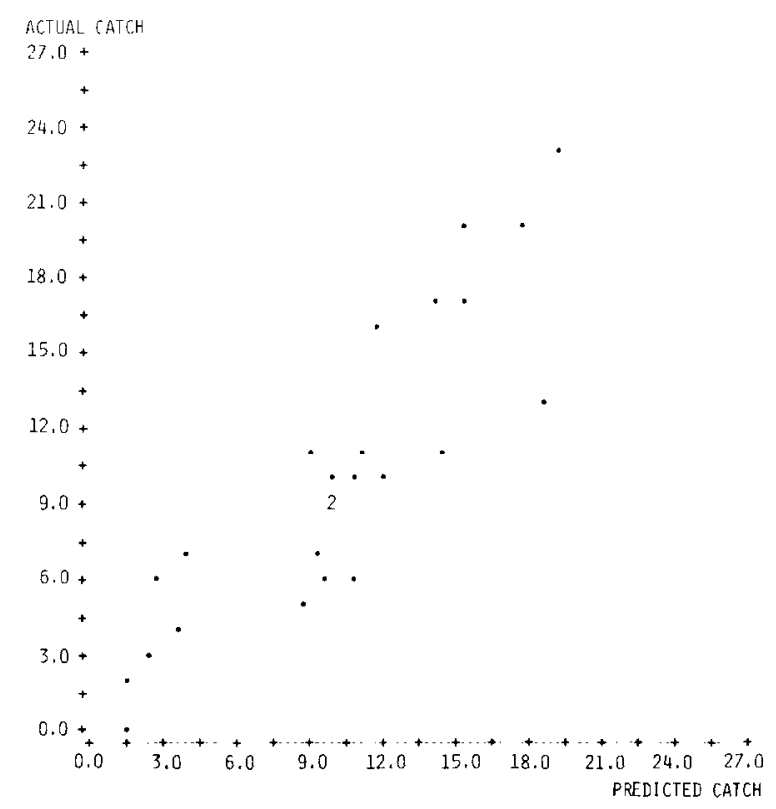

FIG. 7. Scatter-plot of predicted vs. actual bowhead catch for Barrow, Alaska.

cycles is supported by low autocorrelation coefficients with a monotonic decrease beyond the first order.

The impact of these fluctuations was potentially mediated by storage of surpluses in ice cellars excavated below the permafrost (Spencer 1959:60; Rasmussen 1927:310). There is no evidence, however, that surpluses were stockpiled against future disaster. Instead, a successful year triggered the fulfillment of a set of social obligations which operated to redistribute annual surpluses within and between communities. In the words of one captain from Point Hope, "What's the point of catching a whale if I don't just give away as much of it as I can?"' (Lowenstein 1981:67, emphasis in the original). As a means to this end, the successful captain and crew sponsored a series of feasts which increased local consumption of whale meat and moved surpluses both between coastal communities and between ecological regions (Burch and Correll 1972; Okakok 1981:559-567; Ray 1885; Spencer 1959:210).

The reliance on social redistribution mechanisms over stockpiling suggests that a community could experience frequent local shortages. Historical sources record that the community at Point Barrow suffered from scarce resources in $1837,1843-1844,1848-1849$, and 1853-1854, for four successive fifth years (Simpson 1875:264), while Spencer (1959:142) notes that every sixth or seventh year might be marked by a winter food shortage. 
TABLE 3

Regression Model for Factors Determining Whaling Success, Point Hope, Alaska:

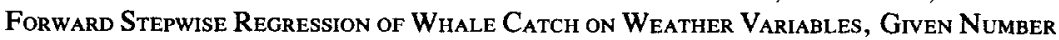
of Active Crews and Changes in Stock Size

\begin{tabular}{|c|c|c|c|c|c|}
\hline \multicolumn{3}{|c|}{ Analysis at Step 1 for Point Hope Catch } & \multicolumn{3}{|l|}{$N=29$ of 46} \\
\hline Source & $d f$ & Sum of sqrs & Mean square & $f$ stat & Signif \\
\hline Regression & 3 & 117.96 & 39.320 & 6.4361 & .0022 \\
\hline Error & 25 & 152.73 & 6.1092 & & \\
\hline Total & 28 & 270.69 & & & \\
\hline
\end{tabular}

Multiple $r=.66013 r^{2}=.43577 \mathrm{SE}=2.4717$

\begin{tabular}{lcccrr} 
Variable & Partial & Coefficient & SE & $t$ stat & Signif \\
\hline Constant & & -4.9507 & 3.9683 & -1.2476 & .2237 \\
Mar. prec & -.46003 & -12.193 & 4.7065 & -2.5906 & .0158 \\
Crews & .38431 & .20609 & $.99014-1$ & 2.0814 & .0478 \\
Stock & .39912 & $.39513-2$ & $.18155-2$ & 2.1765 & .0392
\end{tabular}

\begin{tabular}{lrl} 
Remaining & \multicolumn{1}{c}{ Partial } & Signif \\
\hline Mar. temp & .18776 & .3583 \\
Apr. temp & .25271 & .2129 \\
May temp & -.23588 & .2460 \\
Jun. temp & .10768 & .6006 \\
Apr. prec & -.10732 & .6018 \\
May prec & -.15403 & .4525 \\
Jun. prec & -.13716 & .5040 \\
Mar. mslp & .00885 & .9658 \\
Apr. mslp & -.00019 & .9993 \\
May mslp & .10062 & .6248 \\
Jun. mslp & -.29867 & .1383
\end{tabular}

Regression of Point Hope Catch Using Forward Selection

\begin{tabular}{cccccccr} 
Step & $r^{2}$ & SE & No. Var & Variable & Partial & Signif \\
\hline 0 & .28431 & 2.7297 & 2 & & In & \\
1 & .43577 & 2.4717 & 3 & Mar. prec & In -.46003 & .0158 \\
\hline
\end{tabular}

No longer term trends in whaling success are apparent in the historic data. Nor have ecological studies of whale populations identified longterm cycles in their population size (Gaskin 1982). Vibe (1967) has presented a model for long-term shifts in the migratory path of the eastern Arctic bowhead in response to the volume of sea ice around Greenland. While heavy sea ice is known to delay the timing of the bowhead migration along the Alaskan coast (Braham et al. 1980; Mitchell and Reeves 1980), the applicability of the Greenland ice data (Koch 1945) for predicting migratory shifts in the western Arctic remains unclear. Similarly, 


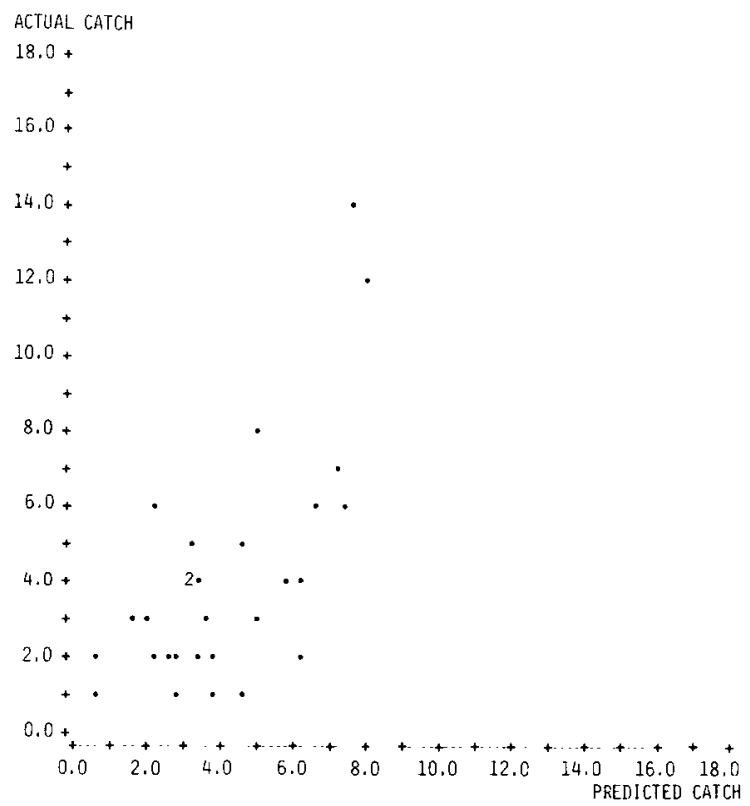

FIG. 8. Scatter-plot of predicted vs. actual bowhead catch for Point Hope, Alaska.

eustatic fluctuations in sea level $( \pm 2 \mathrm{~m}$ ) over a period of several hundred years (Hume 1965) have a potential, but at present unknown, effect on the accessibility of the migrating bowhead population (Stanford 1976)..$^{5}$ However, possible long-term fluctuations in the availability of whales along the northwest coast of Alaska may be proposed from the impact of local weather on whaling conditions.

The development of weather patterns in northwest Alaska is controlled, at the synoptic level, by the relative strength and position of two

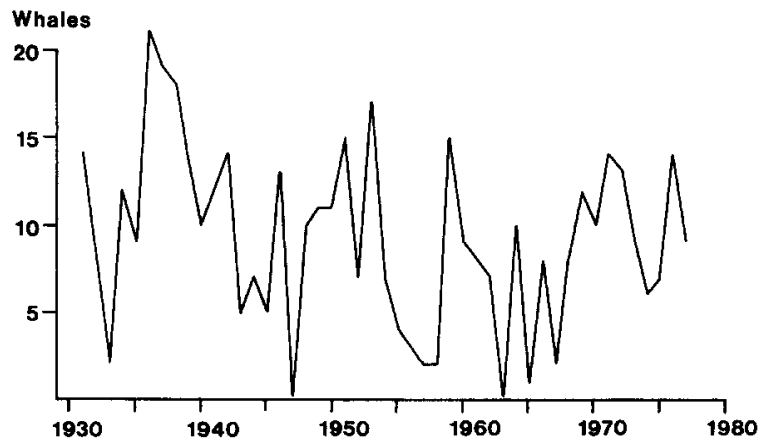

Fig. 9. Annual whale catch predicted from variability in weather conditions, Barrow, Alaska, $1931-1977$. 
air masses: the Arctic high descending from the polar cap, and the Pacific maritime high originating over the Pacific Ocean at mid-latitudes (Allen and Weedfall 1966; Barry and Chorley 1982:152-161; Haugen and Brown 1980; Myers and Pitelka 1979). A weakening of the north Pacific high and descent of the Arctic air mass creates anomalous high pressures over the Beaufort Sea and most of Alaska. Persistence of an early Arctic high pressure system inland generates clear, dry conditions over continental Alaska (Cropper 1982:237-238) which hasten the rate of snow melt and subsequent sea ice break up and sea breeze development. Alternatively, the easterly displacement and general depression of the Arctic high, and a corresponding strengthening and northern extension of the Pacific high generates anomalous low pressures over Alaska (Barry and Chorley 1982:174; Cropper 1982). A late spring and somewhat cooler and wetter summer conditions result over interior Alaska (Cropper 1982). The heavier volume of summer sea ice and restricted open water associated with the weakened Arctic high are attributed to these lower temperatures (Rogers 1978; Barnett 1976). The coastal region experiences a reduced spring influence of Arctic maritime air, with cooler temperatures and less precipitation, i.e., conditions which favor successful whaling.

Temporal variability in the relative dominance of these large-scale pressure anomalies has been reconstructed using dendroclimatological data (Cropper 1982). As noted previously, Cropper related wide trec-ring widths in Arctic spruce to an anomalous Arctic high, while below-normal tree growth resulted from a displaced and weakened Arctic high and the northern advance of a strengthened Pacific maritime high. The reconstructed climatic sequence (Fig. 5) based on tree-ring chronologies from the interior of Alaska (Giddings 1941) indicates alternating centuries of above-normal growth (Arctic high) followed by an equivalent period of below-normal growth (Pacific maritime high). On the coast, these growth patterns correspond to periods of relative maritime and continental conditions, respectively. If we can extrapolate from the short-term effects of weather on whaling success, then it appears that the northwest coast would experience long-term cycles alternating between Arctic maritime conditions which adversely affect whaling, and continental conditions which favor whaling success.

Spatial impact of variable whaling success. Interannual fluctuations in whaling success were experienced at the level of the local community. On an annual basis, the success of one community was relatively independent of that of the others. Between 1940 and 1977, the annual catches of Barrow and Point Hope show only a weak relationship $(r=.43)$, in spite of the strong correlation in the level of whaling effort (number of active crews) at these two communities $(r=.85)$. The differential success in whaling may reflect variability in the spatial scale of weather pat- 
terns determining whaling conditions. Weather values from the Barrow station were good predictors of local whaling success but were less accurate indicators of whaling success at Point Hope. Over the longer term, however, the persistence of an Arctic high-pressure system creates more frequent years of adverse whaling conditions and increases the probability of a poor year at any one coastal community. As a result, the spatial impact of long-term cyclical weather patterns would reduce the productivity and reliability of the coastal zone as a whole.

In summary, whaling success along the northwest coast of Alaska is largely determined by the impact of weather on local whaling conditions. Historical changes in the intensity of whaling effort or the size of the Pacific bowhead stock have had comparatively little effect on annual catch. In the short term, whaling success is highly variable, such that a coastal community dependent on whaling may experience scarcity as frequently as one year in five. Over the longer term, the persistence of large-scale pressure systems which adversely affect whaling conditions create periods in which bad years are experienced with greater frequency along the entire coastal zone. Support for these long-term cycles is lacking in the historical record of shore-based catch; however, major oscillations in regional weather patterns at an interval of approximately 100 years are apparent in the dendroclimatological sequence.

\section{The Temporal Relationship between Coastal and Inland Resources}

The persistence of specific pressure anomalies creates conditions which alternately favor the reproductive success and abundance of inland caribou, and the whaling success and local availability of the Pacific bowhead. The warm, dry inland conditions associated with an Arctic high were found to be favorable for the success of the caribou population, but to adversely affect whaling through an early or intensified development of the sea breeze. Under the cool, wet influence of the Pacific maritime high, the caribou herd declines, while whaling conditions along the coast should be improved by the continental character of the Arctic system. Over the long term, the coast and the interior constitute complementary zones based on the alternate availability of their faunal resources.

\section{STRATEGIES FOR SURVIVING SUBSISTENCE CRISES}

Shortages in both the arctic caribou and the bowhead whale occurred on three scales. Seasonal shortages were anticipated regularly with the natural migratory movements of the species through a hunter's territory. Stochastic interannual shortages, consisting of a shift in the migration path of the caribou or an unsuccessful spring whaling season, created a 
potential crisis situation every 10 to 20 years inland, and as frequently as 1 in 5 years along the coast. The spatial impact of interannual shortages was variable, affecting the territory of one or more regional groups. Long-term cyclical fluctuations in resource availability occurred due to variation in arctic weather patterns which reduced the caribou population or generated adverse whaling conditions over a period of several decades to a century. The large scale of these weather systems affected the productivity of an entire habitat zone and created regional subsistence crises.

The strategies employed to buffer subsistence crises and the social means of implementing those strategies varied according to the severity of the crisis in terms of temporal duration and spatial scale.

Survival of seasonal food shortages relied on the strategies of specialization, maximization, and storage. In harvesting the primary faunal resource, no preconceived level of sufficiency determined when hunting operations should cease. Active whaling continued until the shore-ice began to break up and the launching of boats became unsafe. While the crews remained on the ice, the Tareumiut pursued every whale that passed within 200 yards of shore (Maher and Wilimovsky 1963). ${ }^{6}$ Among the Nunamiut, the spring caribou hunt continued for as long as contact could be maintained with the herd (Spencer 1959). During the drive, hunters focused on the young bulls as the largest meat-bearing animals; boys were stationed at the far end of the corral to let cows and calves out and make room for more bulls to enter the impound (Binford 1978; Rausch 1951). Considerable surpluses of whale meat were preserved through freezing in ice cellars below the permafrost, while caribou meat was dried or frozen, and cached.

The effectiveness of maximization as a strategy for survival of seasonal shortages depended on the pooling of labor and resources. At the local level, kinship ties and the voluntary association of the hunting crew provided the requisite means of social integration.

Kinship rights and responsibilities were held inviolable, and socialization of children included learning the names and appropriate kinship designations for all relatives of whom one might seek assistance and to whom one owed assistance in return. Three levels of kinship affiliation provided an expanding network of economic obligations which an individual could utilize in times of need:

The nuclear family or ketuuneraareic functioned as the minimal unit of co-residence, production, and consumption. Economic bonds within the family were those of a partnership based on the sexual division of labor. Proceeding from the individual along maternal, paternal, and affinal lines, the extended family or iilyagiic established kinship ties and incumbent responsibilities over a broader geographical area. Extended family claims 
to assistance centered on the obligation to share food and grant shelter in times of need.

At a tertiary level, each extended kin grouping or regional group identified itself with a territory whose geographic name the group bore. The nunatqatigiit included those people "who are related to one another through their common ownership of land" (Burch 1981:11). As a social entity, the regional group delimited the normal marriage universe of interrelated kinsmen. Anyone outside this unit was by native definition a stranger (Burch and Correll 1972).

Cross-cutting these kinship ties were the economic bonds formed through association with a hunting crew. The hunting crew was organized during the annual hunt as the minimal work unit necessary to maximize the seasonal take of the primary resource. The crew consisted of eight or nine able adult malcs recruited from the local community, voluntarily aligned with and directed by the umealiq or "wealthy man" (Spencer 1959, 1972; cf. Burch 1975 for an opposing view of the hunting crew as a primarily kin-based unit). Among the Tareumiut, the umealiq owned and provided the boat and gear for the whale hunt and acted as its captain. In the case of the Nunamiut, the umealiq was responsible for planning the annual caribou drive and organizing the construction of the corral.

The hunting crew gained a year-round cohesiveness through its association with a karigi or "men's house," and the major social activities of the karigi reflect the continued economic obligations of that unit. Throughout the winter men shared their meals in the karigi, allowing for the redistribution of food from individual stores. The karigi of a successful umealiq additionally sponsored a series of feasts which further redistributed local surpluses of meat within the community (Burch and Correll 1972; Gubser 1965; Okakok 1981; Spencer 1959, 1972).

In contrast to regularly anticipated seasonal shortages, interannual variability involved the failure of the primary resource over a period of at least a year. In the long term, severe shortages could extend over decades. Survival of a resource crisis of this scale depended on a strategy of mobility and the social mechanisms which enabled the redistribution and relocation of the population relative to available resources. Access to resources, however, was not guaranteed. Relations between territories were frequently antagonistic; strangers were treated with suspicion and hostility, and crossed territorial boundaries either under the sponsorship of a predefined alliance or at considerable risk (Burch and Correll 1972; Spencer 1959).

Cultural buffers to crisis-level resource variability consisted of social linkages which granted access to locally abundant occurrences of a major resource. Burch and Correll (1972) have identified two forms of alliance 
which granted social access across territorial boundaries: intermarriage and trading partnerships.

While family membership constituted the strongest social bond, kinship contacts were geographically constrained. Marriage ties between territories of the same resource zone were uncommon; marriage across the boundaries of habitat specialization was not economically feasible. To take a partner untrained in the skills necessary for survival in one's own habitat was a luxury that a man could ill afford (Spencer 1959:76). The utility of kinship as a buffering mechanism was accordingly limited to crisis situations over a limited spatial scale.

The primary link between territories and the only formal link across regional boundaries was that of the trading partnership, either between two members of the same resource zone, or between a Tareumiu and a Nunamiu (Burch 1970). Formal trading partners referred to one another as nyuuviq. This term signalled a special status between the two members, conferring economic advantages and social guarantees. Economically, a man with a trading partner from a different habitat zone was assured of attaining goods considered essential for survival on an annual basis, the Tareumiut exchanging food and fuel in the form of whale and seal oil for the caribou skins of the Nunamiut used for clothing. Annual surpluses were reserved for the benefit of one's partner and a general ethic of liberality presided over the exchange.

A man also attained direct social access to other territories through the sanction and protection of his partner: "If a man had a partner in any community, he could go there freely and count on the protection of his mate ... In such cases, the visitor would not fall into the category of 'stranger' and so be subjected to hostile acts from within the community" (Spencer 1959:168). In times of abundance, trading partnerships were cemented through wife exchange, increased levels of trade, and invitations to intercommunity feasts such as the mid-winter Messenger Feast (Burch and Correll 1972). In times of need, the social protection of a partner could be amplified into actual assistance. "In partnerships, just as a man might ask and receive aid from his relatives, so also could he make demands of his partner. Protection and refuge, goods, food, and sexual favors, in the form of wife lending and exchange, were to be had from partners" (Spencer 1959:170).

Trading partnerships were established widely between regions. While every adult male tried to have at least one partner, there was no upper limit, except financial and social obligations, on the number of partnerships in which one could engage. ${ }^{7}$ Individuals would seize on any material basis to recruit a partner, and in many cases trading was as symbolic as it was substantive in nature (Burch and Correll 1972). As a result, an 
individual could gain economic and social access to a number of different territories or regions simultaneously. In the short term, alliances with adjacent territories were sufficient. Over the longer term, however, survival during a regional resource failure may have depended on one's partner in a complementary resource zone.

In summary, an individual belonged to an array of kinship units and voluntary associations which gave him access to an increasing geographic area and hence to a broader range of subsistence resources. Participation in a hunting crew and its respective karigi operated to link individuals into a system of mutual rights and obligations at the level of the local community. The nested kinship units of nuclear family, extended family, and regional group established linkages of reciprocity between individuals within a given territory. Finally, trading partnerships provided similar links with other territories and with alternative resource zones.

Up to this point, the study has focused on the levels of variability in subsistence resources to which the Tareumiut and Nunamiut must respond over time, and the possible alternative strategies and social mechanisms for countering resource fluctuations of different scales. The remainder of the study evaluates the role of oral tradition in storing information concerning these crisis situations and appropriate strategies for survival.

\section{ORAL TRADITION AND INFORMATION TRANSMISSION IN TAREUMIUT AND NUNAMIUT SOCIETY}

Oral tradition is distinguished from transitory verbal communication by its occurrence within a structured social context that establishes the means appropriate for both the encoding (storage) and decoding (retrieval) of information. Using the criterion of a structured social context, six basic forms of oral tradition can be identified for the Tareumiut and Nunamiut: (1) insult song exchanges; (2) magical hunting songs; (3) folktales; (4) histories; (5) myths; and (6) hunting rituals and associated tabus. Of these, insult song exchanges, magical hunting songs, and histories wcre cxcluded from the present study.

The exchange of insult songs between trading or hunting partners consists of a competition in the creative use of plays on words, puns, and mild insults, which has been interpreted as a means of resolving conflict between individuals or as a release of built-up tension (Eckert and Newmark 1980). While insult song exchanges serve to stabilize interpersonal relationships which are crucial to survival, this medium does not appear to directly encode information concerning resource crisis situations.

Supernatural or magical hunting songs (aatuutit), on the other hand, accompanied virtually every act of hunting to control the behavior of 
game, weapons, and the weather (Spencer 1959:278). While this aspect of compulsive magic may encode information of survival value, the private nature and limited use of these songs has made it difficult to collect an adequate sample for analysis. Similarly, native histories are underrepresented in the ethnographic accounts. A more detailed presentation of the context and content of folktales, myths, and major hunting rituals and tabus follows.

\section{The Context Provided by Folktales and Myth}

Both the Tareumiut and the Nunamiut make a primary distinction in oral literature between true history (koliaqtuaq or oqaluktoq, respectively), and imaginary folklore (unipqaq or unipqok) (Rainey 1947:269; Gubser 1965:28-29). Koliaqtuaq, literally "it has been told," comprises factual, authentic incidents occurring from the time of creation down to present day. The fictional unipqaq from the verb "it seems like," refers to situations which were purely imaginary.

History and fiction are distinguished through the use of specific temporal referents in the narrative. Within the stretch of historical time, a threefold division is made (Gubser 1965:28). Itchaq imma ("very early days") is the earliest period beginning with the creation of the Tareumiut or Nunamiut people and ending with the destruction of superhuman beings during the most recent glaciation. Inilagaan ("early days") begins technically with the recession of the glacier, but the history of the period is coherent only from the late $1700 \mathrm{~s}$. The third period, ipani or "personal remembrance," includes the memory of the events of an individual's own lifetime. In contrast, fiction has no specified time referent (Fig. 10).

The use of time depth to signal the veracity of transmitted information suggests three operational categories of secular oral literature: (1) the time honored accounts of itchaq imma, which will be referred to as myth; (2) the historical accounts of inilagaan and ipani, termed histories; and (3) the atemporal, fictitious accounts of unipqaq, or folktales. Unfortunately, an insufficient sample of the historical accounts from the late 1700 s to the present day precludes this second category from the present study.

The telling of folktales and myths took place primarily in two recreational settings: the communal karigi activities of the winter months and the summer trade fairs (Hall 1975:39; Spencer 1959:383). During the winter, women and children joined the men in the karigi on the occasion of storytelling, so that the contents of folktales and myths were equally available to all members of society. Similarly, a social highlight of the trade fairs was the chance to itqaaq, i.e., "recall happenings of long ago" 

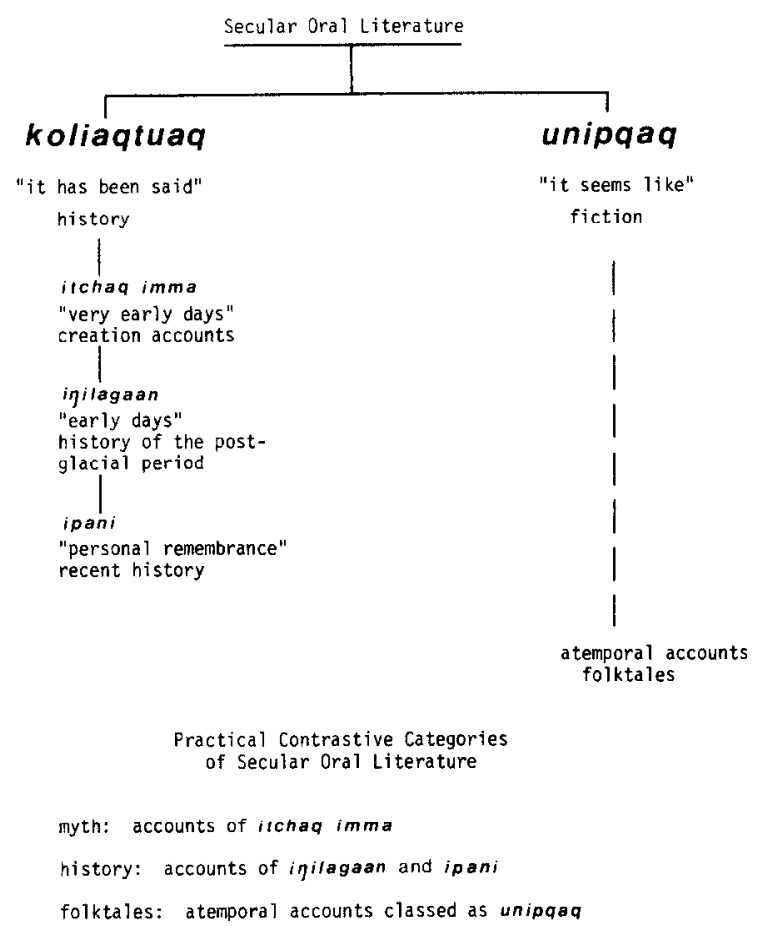

FIG. 10. Native conceptual categories of secular oral literature.

with one's partner, resulting in the active transmission of folktales and myths between regions and groups (Okakok 1981:624).

Folktales and myths were also consulted to establish a precedent for appropriate beliefs and behavior in times of uncertainty: "An unusual circumstance, a conflict of opinions, or a special difficulty demanded the recitation of either of the two types of tales to determine the course of action to be followed" (Rainey 1947:269).

In Eskimo society, anyone who wished could tell any story. There was no formal means of acquiring this skill and knowledge. An individual learned a story merely by listening to it carefully at every opportunity. There were, however, certain restrictions on how the art of storytelling should be conducted. First, custom demanded that a storyteller tell at least two tales at a given session, thereby increasing the number of stories in active circulation (Hall 1975:410; Spencer 1959:384). Second, a story had to be told correctly, that is, exactly as it was heard, and in its entirety (Hall 1975:39; Spencer 1959:383). If a narrator deviated by a single word in his recital, his skill was considered dubious. While an individual could create a new story surrounding a current or local event, 
once told, it was incumbent on the listener to retell the new tale exactly as first pronounced.

The exact recitation of folktales and myths was a cultural ideal, not a reality (Hall 1975:39). While this cultural ideal did not necessarily preclude error in transmission, it did potentially create a secular oral medium which was fairly retentive of encoded information.

\section{The Context Provided by Major Hunting Rituals and Tabus}

For the purposes of the present study, religious ritual comprises those prescribed performances and formal actions manifestly directed toward the involvement of supernatural agencies in the affairs of the actors (Rappaport 1979:28). Tabus, in contrast, consist of the complementary set of ritually restricted or proscribed behaviors.

As a performance, ritual provides a context for the transmission of information on two distinct levels: indexical and canonical (Rappaport 1979:179). At the core of the religious ritual order are those invariant and symbolic acts which communicate canonical principles concerning the structure of nature, society, or the cosmos. In endeavoring to manipulate the spirit world to man's benefit, ritual performance provides a physical enactment or model of the way in which the natural world operates according to native beliefs. At a secondary level, however, ritual performance also provides a context for the transmission of more transitory information concerning the current physical, psychological, or social states of the participants. This indexical information depends on direct representation, such as who participates in the ritual and in what capacity, to communicate the individual's status in the immediate social situation.

The primary communal rituals of the Tareumiut and Nunamiut surrounded the spring whaling season on the coast, and the caribou drives in the interior. During the spring hunt, the core of the ritual group was formed by the hunting crew of the karigi association. Through kinship ties with the men of the hunting crew(s), the entire community was simultaneously involved in the ritual proceedings. Within the community, however, special ritual roles were reserved for the umealiq or captain, the umealiq's wife, and an agent of the supernatural who acted as spiritual advisor for the group.

The rituals and tabus of the spring hunt were based, as were all hunting practices, on the belief that animals have both a species and an individual spirit, which endow them with the power of omniscience and the ability to reincarnate. As a rule, "an animal did not object to being killed, so long as proper and respectful treatment was forthcoming on the part of the slayer. If offended, the released animal spirit told the other animals 
what had happened and the game remained away" (Spencer 1959:264). If treated properly, the spirit would reincarnate and return repeatedly to the respectful hunter.

The rituals and tabus of the spring hunt accordingly had two overt purposes: (1) to magically control the animals and induce them to come to the hunters; and (2) to ensure proper treatment of the animals once they had been taken to avoid giving offence to their spirits (Spencer 1959:264). The means to effect these dual ends constituted a demonstration of solemn respect for the hunted animals.

The guidelines for respectful behavior and its ritual expression had been established by tradition, and the correct ritual performance and observation of tabus received strong supernatural sanction. Failure to conduct the prescribed ritual sequence or to observe a proscription was synonymous with disrespect and could bring disaster to the hunt unless remedied. A large portion of the ritual activities had therefore acquired an invariant order through time. 8

The performative elements of (1) ritual actors, and (2) ritual activities, provide distinct opportunities for the incorporation of new information, as well as for noise or distortion, into the medium of hunting rituals. Eligibility for positions of ritual leadership was defined on the basis of social standing. As the degree of ritual participation varied with changes in the social order, the communal ritual potentially served as a context for the communication of indexical information concerning current social relations within the community. In contrast, the performance of ritual action was largely constrained by an invariant order of reproduction sanctified by supernatural beings - a sanction guaranteeing the transmission of canonical information encoded in that ritual action.

\section{The Potential for Encoding Survival Information}

The preliminary model outlined above suggests that various oral media will record information of different time depth and content according to (a) the degree of accuracy or longevity, and (b) the accessibility of the information as dictated by the respective contexts. Two ideal types of contrasting social contexts were proposed: secular and sanctified. In the case study of the Tareumiut and Nunamiut, the oral traditions conform well to these proposed ideal types, and are expected to encode information relative to different time scales as predicted by the model.

Two distinct levels of accuracy or longevity of encoded information are created by contextual constraints which guard against error in transmission. The secular oral traditions of folktales and myths rely on a cultural ideal of exact recitation; myth additionally employs historical time depth to attribute greater validity and immutability to the encoded information. 
In contrast, religious hunting rituals and tabus employ a supernatural sanction backed up by a fear of failure in the hunt. The combined force of the supernatural and starvation wields a much stronger constraint on the introduction of variability than that of a cultural ideal. As a result, information transmitted through rituals and tabus will endure over greater periods of time than that encoded in folktales or myths. Within the body of secular oral tradition, myth ensures more reliable transmission through time than do folktales.

The two social contexts of oral traditions also contrast in terms of the accessibility of transmitted information. The primary communal rituals and tabus involved considerable energy investment and were temporally concentrated during the spring hunting season, thus reducing the accessibility of information encoded within them. These media are appropriate only for the transmission of survival information needed at infrequent intervals. In contrast, the telling of a folktale or myth could be concluded in an evening's entertainment whenever the opportunity arose. Information encoded in folktales and myths was more readily available in the short term. Little contrast exists between the two media in terms of their spatial availability. Ritual actions were motivated by a supernatural sanction which was shared across the boundaries of distinct resource zones; folktales and myths were actively exchanged between groups.

Based on the preceding differences in the accuracy and accessibility of information, it is expected that the body of Tareumiut and Nunamiut oral traditions will transmit information relevant to resource crises on at least two temporal scales. Folktales and myths are appropriate media for the transmission of information pertaining to short-term resource crises, including seasonal and interannual shortages of the primary faunal resources. In contrast, the major hunting rituals and tabus are expected to contain strategies for long-term survival, across regional failures of the caribou population or periods of reduced whaling success on the coast.

\section{Content of Secular Oral Tradition}

The nature of information encoded in secular oral traditions was assessed through a qualitative and quantitative content analysis of 54 Nunamiut and Tareumiut accounts. 9 The accounts were classificd as myth if they were framed, either verbally or contextually, within the "very early days" and related specific historical events, such as the creation of the world or the origin of a particular geographic feature or social custom. Folktales, in contrast, were identified by the absence of specific temporal or historical referents, or by the use of very general time markers, such as "once long ago" or "in bygone days." The data base consisted of published translations of field recorded texts attributed to a Tareumiu or 
Nunamiu informant (Gubser 1965; Jenness 1926; Murdoch 1886; Ostermann and Holtved 1952; Spencer 1959).

The content analysis of the myths and folktales utilized a procedure similar to that of the "general inquirer method" (Colby et al. 1963). In this approach, a list of content themes or key words covering topics of interest is generated. Each story in the sample is then checked against the list for references to the selected theme.

In the analysis of Tareumiut and Nunamiut accounts, 32 recurrent themes were selected as reflecting the strategies and social mechanisms for coping with environmental stress. A theme was identified as having survival value if it referenced a tactic appropriate for mediating the spatial and temporal impact of resource fluctuations as predicted by the preceding models of variability in primary faunal resources.

Survival themes relevant to three different spatiotemporal scales of resource deprivation were recorded (Table 4). The first group of survival themes involves subsistence practices for coping with seasonal shortages

TABLE 4

Content Themes in Tareumiut and Nunamiut Folktales and Myth

I. Themes contributing to survival in the short-term

A. Short-term strategies

1. Specialization/abundance of own habitat zone

2. Maximization

3. Storage

B. Social mechanisms relating to pooling of labor and resources

4. Socialization of traits relating to group maintenance: consideration and respect for others; control of emotion/anger; need to be happy, appreciative

5. Cooperation within the group/being helpful

6. Obligation to share within the group

7. Generosity

8. Obligation for self-support; hard-working, industrious, not lazy

9. Resourcefulness/cleverness

10. Supernatural sanction of social values: animals allow themselves to be taken by "good" people: animals can avoid or bring harm to "bad" people

11. Reference to kinship ties (family/marriage/children)

12. Family as unit of production and consumption: need for spouse to balance work-load or children to help support parents in old age

13. Orphan as pitiable figure or poor; has no one to hunt for him

14. Family size/ties as a measure of social strength or wealth

15. Importance/strength of kinship ties: love between family members; following, mourning or revenging kinsman

16. Responsibility of umealiq to feed community

17. Strangers to be treated with suspicion; unknown territories or communities dangerous 
TABLE 4-Continued

II. Themes contributing to survival of inter-annual crises

A. Strategies

18. General mobility/travel

19. Intrahabitat movement in times of stress

20. Use of secondary resources in times of stress

B. Social mechanisms

21. Intercommunity marriage (within same habitat)

22. Intercommunity feasts

III. Themes contributing to survival of long-term, regional crises

A. Strategies

23. Ecological/economic generalization; use of both land and sea

24. Resource potential of other habitat zones

25. Interhabitat zone movement in times of stress

B. Social mechanisms

26. Interhabitat zone marriage

27. Interhabitat zone trade

28. Interhabitat zone feasts

29. Inability to hunt effectively in unfamiliar resource zone: necessity for social contact to survive or learn skills

IV. References to hardship

30. Seasonal shortages or hardship (winter/spring)

31. Famine/starvation/death

32. Climatic change and impact on resources

of the primary resource (No. 1-17). Strategies appropriate for mediating annually anticipated shortages include the specialization on, and maximization of, the primary faunal resource, and storage of surpluses. The implementation of these strategies requires pooled labor and resources, and depends on attitudes and behaviors which maintain group solidarity, as well as the recognition of economic obligations associated with community membership.

The second thematic group concerns the survival of interannual resource variability and crisis situations (No. 18-22). Strategies for surviving the short-term, localized failure of the primary resource include increased mobility, movement between territories of the same habitat zone, and increased use of secondary resources. Social access to nonlocal resources was provided through kinship ties of intercommunity marriage and reinforced through intercommunity feasts.

Themes encoding survival strategies relevant to long-term crises constitutc the third group (No. 23-29). The regional failure of the primary resource required emigration to another resource zone, and was facilitated by a strategy of economic generalization (ability to use both marine and terrestrial faunal resources), and a knowledge of the resource potential of another region. Social linkages between resource zones were 
formed through interhabitat zone marriage, trading partnerships, and feasts.

A final, related group of themes record references to hardship on two levels: seasonal shortages or hunger, and actual famine or starvation of the group (No. 30-32).

The procedure for evaluating the treatment of these themes in the present sample of myth and folktale consisted of first outlining the primary sequence of events or narrative comments in each account. These synopses were then annotated with code numbers identifying specific themes (Table 4), and the references to each theme tabulated (Table 5). ${ }^{10}$ The results of this tabulation were summarized quantitatively as the percentage of the accounts containing a reference to a specific theme, or the frequency of occurrence of a theme within this body of oral literature (Table 6).

No systematic search for themes regarded as interfering with or countering survival success was implemented. Obvious counter-productive themes include those strategies which inhibit either the redistribution of resources to people or of people to resources in a crisis situation. The lack of a rigorous evaluation of contradictory themes is a methodological weakness of the present study; however, multiple readings of the myth and folktale accounts indicate that such themes constitute a minimal part of the information transmitted in this body of oral literature. A qualitative discussion of the survival information contained in myth and folktales follows.

Content of myth. Creation myths of the Tareumiut and Nunamiut consist largely of explanatory accounts concerning the origin of the world and its successive transformations to its present state. At the beginning of time, the world was a dark and watery place. Raven, a trickster who could readily assume human form, created the mainland by harpooning either a tussock of grass or a giant sea animal, and holding it firm while the waters receded (Ostermann and Holtved 1952:151, 225; Spencer 1959:384-385). Raven is also attributed with the origin of light, by stealing and breaking open a bright ball which had been withheld from the people by a greedy individual (Gubser 1965:35; Spencer 1959:384-385). Other creation myths relate the origin of people and of specific animals, including caribou and fish (Murdoch 1886:594-596). Most of these myths appear fragmentary in nature, and incorporate content themes relevant for survival only at a very low frequency (Table 6).

In addition to accounts of physical creation, the myths record the origin of specific social customs or institutions. Two institutions in particular are treated in great detail, those of trading partnerships and the Messenger Feast, both of which have been identified as critical for establishing social access to alternative resource zones in times of need. 
TABLE 5

References to Survival Themes in Tareumiut and Nunamiut Mrth and FolkTALE ACCOUNTS

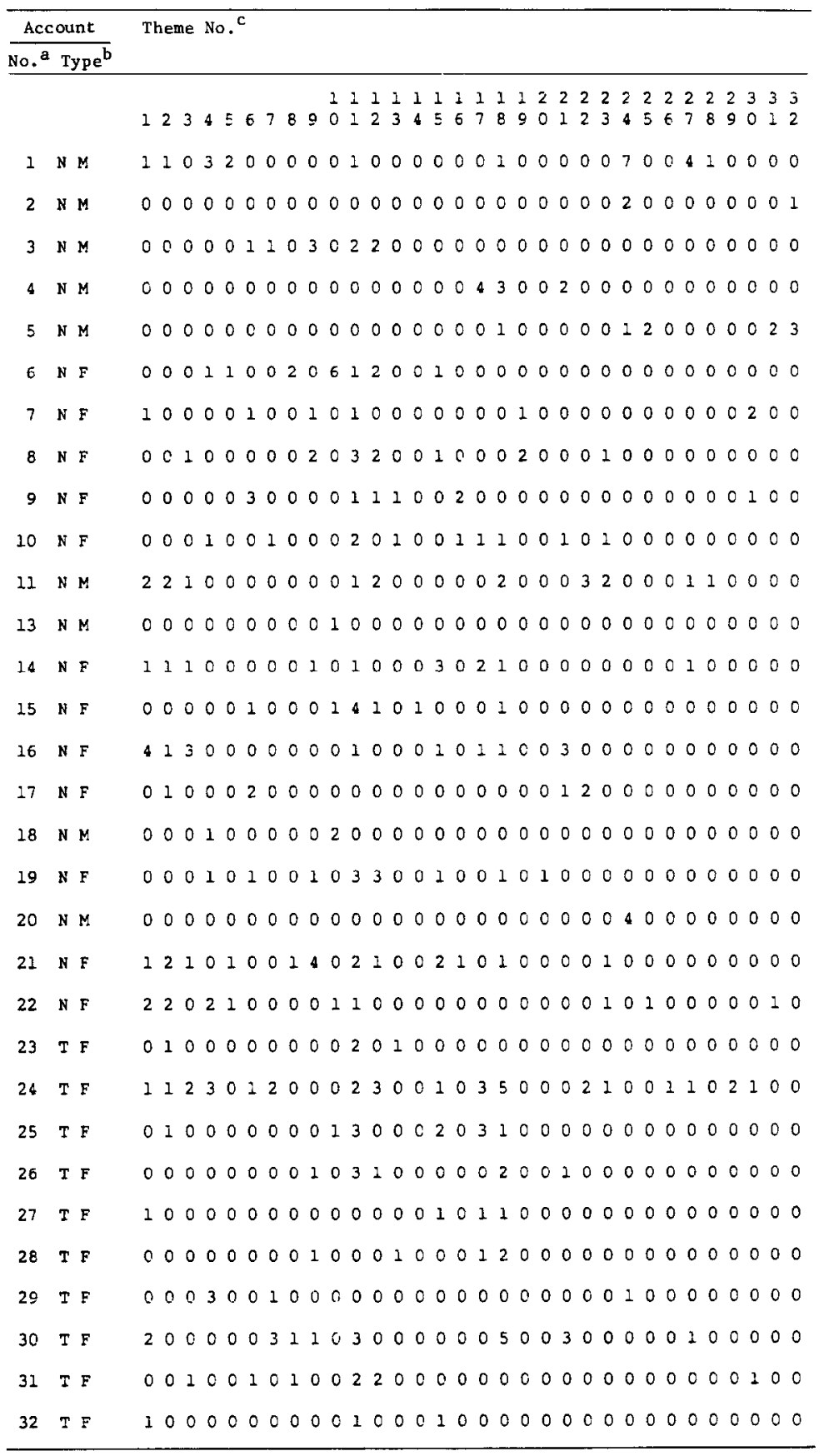


TABLE 5-Continued

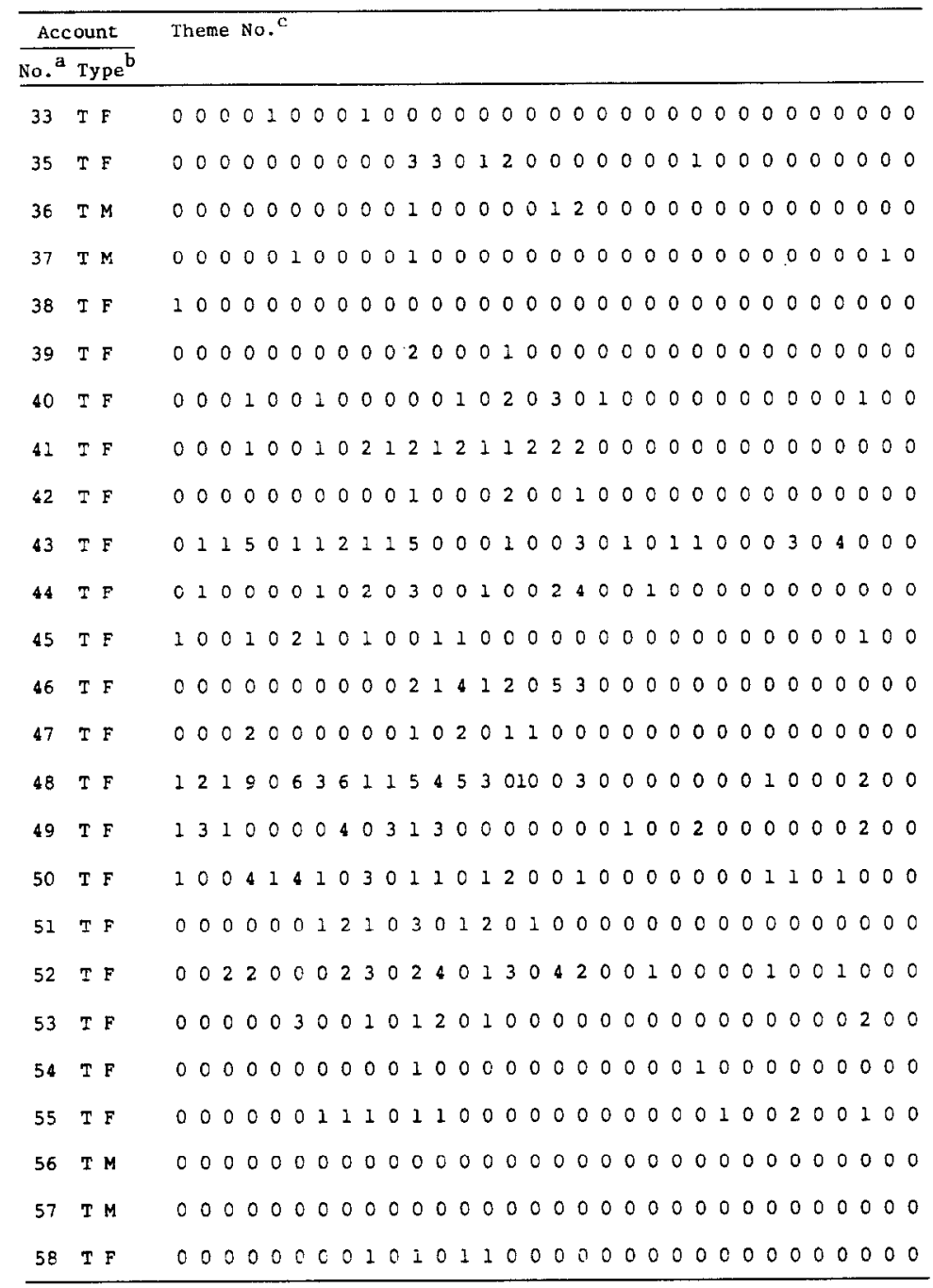

a See Note 9 for identification of account and reference.

${ }^{b}$ Source of account $(\mathbf{N}=$ Nunamiut; $T=$ Tareumiut $)$; type of account $(\mathbf{M}=\mathbf{M y t h} ; \mathrm{F}=$ Folktale),

$c$ See Table 4 for identification of theme number. 
TABLE 6

Presence of Themes in Myth and Folktale

\begin{tabular}{|c|c|c|c|c|}
\hline \multirow[b]{2}{*}{$\begin{array}{l}\text { Theme } \\
\text { number }\end{array}$} & \multicolumn{2}{|c|}{$\begin{array}{c}\text { Myth } \\
(N=12)\end{array}$} & \multicolumn{2}{|c|}{$\begin{array}{c}\text { Folktale } \\
(N=42)\end{array}$} \\
\hline & $\begin{array}{l}\text { Percentage of } \\
\text { sample }( \pm)^{a}\end{array}$ & $\begin{array}{l}\text { Number of } \\
\text { occurrences }^{b}\end{array}$ & $\begin{array}{l}\text { Percentage of } \\
\text { sample }( \pm)\end{array}$ & $\begin{array}{c}\text { Number of } \\
\text { occurrences }\end{array}$ \\
\hline 1 & 17 & 3 & 31 & 19 \\
\hline 2 & 17 & 3 & 29 & 17 \\
\hline 3 & 8 & 1 & 24 & 14 \\
\hline 4 & 8 & 4 & 33 & 36 \\
\hline 5 & 8 & 2 & 12 & 5 \\
\hline 6 & 8 & 1 & 29 & 26 \\
\hline 7 & 8 & 1 & 31 & 18 \\
\hline 8 & 0 & 0 & 24 & 22 \\
\hline 9 & 8 & 3 & 45 & 29 \\
\hline 10 & 17 & 3 & 19 & 15 \\
\hline 11 & 33 & 5 & 81 & 70 \\
\hline 12 & 17 & 4 & 45 & 37 \\
\hline 13 & 0 & 0 & 26 & 20 \\
\hline 14 & 0 & 0 & 24 & 13 \\
\hline 15 & 0 & 0 & 48 & 31 \\
\hline 16 & 0 & 0 & 19 & 18 \\
\hline 17 & 8 & 5 & 29 & 28 \\
\hline 18 & 42 & 9 & 48 & 41 \\
\hline 19 & 0 & 0 & 7 & 4 \\
\hline 20 & 0 & 0 & 7 & 3 \\
\hline 21 & 8 & 2 & 14 & 11 \\
\hline 22 & 8 & 3 & 7 & 5 \\
\hline 23 & 8 & 2 & 19 & 10 \\
\hline 24 & 33 & 14 & 2 & 2 \\
\hline 25 & 8 & 2 & 2 & 1 \\
\hline 26 & 0 & 0 & 12 & 4 \\
\hline 27 & 17 & 5 & 14 & 9 \\
\hline 28 & 17 & 2 & 0 & 0 \\
\hline 29 & 0 & 0 & 9 & 8 \\
\hline 30 & 0 & 0 & 24 & 14 \\
\hline 31 & 8 & 2 & 2 & 1 \\
\hline 32 & 17 & 4 & 0 & 0 \\
\hline 33 & 33 & 8 & 55 & 69 \\
\hline
\end{tabular}

a Percentage of sample refers to the portion of the sample containing a reference to the theme as recorded on a presence/absence basis.

${ }^{b}$ Number of occurrences indicates the total number of times a theme was referenced in this collection of accounts.

According to one Nunamiut myth, trade and feasting between the Nunamiut and other groups was initiated by their creator and culture hero Aiyagomahala in the very early days of the world: 
... Aiyagomahala told his people to hunt as much as they could and collect all kinds of inland animal skins. Caribou, mountain sheep, wolf, wolverine, lynx, grizzly bear, black bear, beaver, marmot, and otter were always around the camp, and the people collected a large number of summer skins. Aiyagomahala told his people that he might call another people to come and trade. In those very early days of itchaq imma no one knew about trading (Gubser 1965:29).

That fall after the freeze-up, Aiyagomahala walked to Point Barrow to establish trade relations with the coastal people. He informed the people at Point Barrow of the people he had created inland and about the resources they had to offer:

He said that they had collected a large number of inland animal skins and inland food, such as dried meat, caribou back fat, some plants, and so forth. Then he told the Point Barrow men that they should travel up to the inland people with seal and whale blubber and sea animal skins which would be a good exchange for the inland products (Gubser 1965:30).

To formalize the trade agreement, Aiyagomahala instituted the Messenger Feast. He advised the Point Barrow Eskimos to prepare a feast for the coming year, and to send two messengers to the head of the Alatna River to announce the feast. Aiyagomahala then initiated trade with other regions and reemphasized the importance of these contacts for the Nunamiut people:

After the inland people learned about the exchange of goods and feasts with the Point Barrow people, Aiyagomahala showed them how to trade with people from other regions. Aiyagomahala told his people that every family, as well as unmarried men, should have a partner in each of the other groups and that nobody should trade with anyone else. From that time on, the Nunamiut greatly cnjoyed giving and attending feasts (Gubser 1965:32).

An alternative account of the origin of intercommunity feasts is treated in the myth entitled "The sacred gift of song, dance and festivity comes to mankind" (Ostermann and Holtved 1952:38-42). In this version, a young Nunamiu is abducted by an eagle, who conveys him to his eaglemother on the peak of a high mountain, in order that the young man may learn the art of song and dance. After the eagle-son and the young man had built a karigi, the eagle-mother instructed them in the art of feasting and dancing:

. . . the eagle-mother taught them to put words together for singing and to arrange tones together so that they became songs, and she showed them how to beat the drum in time with the songs; and finally she taught them how to dance. And when they had learned all this and could do it she said:

"But first you must gather a lot of meat, then many people, when you have built yourself a festival house and composed your songs. Then you must hold a songfeast."

"But we don't know anyone except ourselves," said the young caribou hunter. 


\begin{abstract}
"Human beings are lonely because they have not the gift of festivity," said the eagle-mother; "make ready as I told you, and when everything is prepared, you must go out and look for people, and you will meet them two by two; but you must get them together until there are many, and invite them to the festival house; then you must hold a song feast."
\end{abstract}

The young man returned to his family and built a large festival house (karigi). When all the preparations had been made, the young man set out across all the valleys and up over the mountains, searching for guests to participate in man's first festival:

\begin{abstract}
Then they held a song-feast. First they gave all their guests food, and when they could eat no more, they gave them splendid presents, both meat and furs. Then came the singing and the dancing. ... They went on singing and dancing all through the night until day began to break. It was only then that the guests left the big festival house.
\end{abstract}

It is apparent from the preceding examples that creation and origin myths do not encode a broad range of survival information (content themes); however, those themes which they do record are treated in great detail. The predominant themes consist of mechanisms which establish social access to another resource zone, i.e., trading partnerships and intercommunity feasting, particularly the Messenger Feast. Both of these themes relate to the survival of long-term resource variability by facilitating interhabitat movement in times of stress. In addition, the myths provide a knowledge of the resource potential of other habitats, through descriptions of the nature and abundance of their faunal resources.

The medium of myth emphasizes the importance of interregional contacts in two ways. First, myth uses considerable time depth to validate the contents of an account. To attribute the origin of these customs to the time when the people themselves were created, is to establish trade partnerships and the hosting of intercommunity feasts as synonymous with human existence. Second, the validity of the tradition is confirmed by its association with the creator figure. The explicit directions given by Aiyagomahala to seek out trading partners and to confirm those ties at feasts essentially represents a supernatural sanction on the formation of widespread social networks.

Content of folktales. In contrast to myth, folktales appear as an active means for enculturating social values and attitudes, and reinforcing social units essential for survival in the short term. Those values promoted most frequently contribute directly to the cohesion of the local group: consideration and respect for group members, suppression of anger and criticism, expression of happiness and appreciation, the need to be cooperative, to share with group members, and to be industrious and resourceful.

Folktales place an equal emphasis on the definition of social units and the economic responsibilities incumbent on social ties. Almost every ac- 
count illustrates the importance of the family as the unit of production and protection. In the absence of parental care, young men and women do not learn the skills for survival; reciprocally, children and grandchildren are welcomed joyously as the means of support in old age. The responsibility of the umealiq represents a second key issue. Social responsibility is commensurate with personal wealth and status. As a wealthy man, the umealiq is both in a position, and under obligation, to provide for needy members of the community.

The high redundancy of the information encoded in folktales is achieved through two literary conventions: the framing of an account, and the use of stereotypic characters. The context of most folktales is established in the first few sentences (Hall 1975:419). The physical setting is specified, the primary characters are introduced, and the social or kinship relationships between them are delineated. Much of the action that follows directly results from the nature of these relationships. The protagonists are not generally named; the storyline develops as a social drama between specific social roles, not as an interaction between individuals.

Social roles frequently appear in predefined form as character stereotypes. Common stereotypes include the arrogant young woman who refuses to marry, the young man who cannot find a wife, the poor orphan boy, the rich umealiq, and the man who kills strangers.

The "arrogant young woman" stubbornly refuses all local suitors. Her parents plead with her to marry, saying that they are getting old and soon will have no one to hunt for them. However, she persists and in her refusal to take a husband she betrays all the care her parents have given her as a dependent. The consequences of her refusal are always negative. In one case, her parents abandon her to her own devices (Jenness 1926:34). In another, the girl marries a well-dressed stranger who turns out to be a raven and spatters her own fine clothes with bird droppings (Ostermann and Holtved 1952:157). In a more extreme case, the men of the community revenge themselves upon the arrogant girl in a gang rape (Ostermann and Holtved 1952:263). In all cases, the retribution for her refusal to marry is presented as justly deserved. The message stressed by the arrogant girl is the necessity for marriage and children to provide a system of social security.

A parallel stereotype is the "young man who cannot find a girl to his liking" (Ostermann and Holtved 1952:159; Spencer 1959:419). Unlike the arrogant young woman, the unmarried young man cannot find a wife because he is too shy, or because he has been too devoted to his sister to notice other women. As a result of parental pressure, he leaves home, usually to find a beautiful and industrious girl from another community. The positive example set by the adventurous young man provides en- 
couragement of extra-local marriage as a means of broadening the network of social contacts.

The "poor orphan" marks the bottom of the social scale (Jenness 1926:35, 36; Spencer 1959:396, 402). He usually lives with his elderly grandmother on the edge of the community, and this spatial separation signals a social distance between his situation and the well-being of the community. The orphan is poor, not only because he has few material goods, but because he is lacking in social relations. He has no one to provide for him, no one to make weapons for him, or teach him how to hunt. He is dependent upon the communal distribution of food in the karigi and he lives off the generosity of the community. With no circle of kinsmen to defend him, the orphan is at the mercy of their collective good-will and is frequently subjected to malicious acts. The orphan represents the most pitiable situation of Eskimo society, and underscores the importance of kinship ties for both economic support and social protection.

At the opposite end of the social scale from the poor orphan is the "rich man" or umealiq (Ostermann and Holtved 1952:159; Spencer 1959:387, 402). The wealth of the umealiq is measured from the number of skins and meat stages he owns, the fineness of his clothing, and the size of his house. Of equal distinction is his social wealth. The rich umealiq usually has a plurality of wives, and a number of fine sons, all of whom are good hunters. The good umealiq always gives generously, contributing to the support of the community from his own stores. Even in times of shortage, he continues to provide for the poor orphan and his grandmother. Moreover, the good umealiq provides social protection, sheltering the orphan from maltreatment at the hands of the community at large. The bad umealiq, in contrast, reluctantly feeds the orphan even in times of comparative abundance, and maligns the boy as a parasite on the community. In delineating the obligations attached to the umealiq's position, the rich man stereotype equates personal wealth with social responsibility.

A final stereotype is that of "the man/monster who always kills strangers" (Jenness 1926:64; Spencer 1959:387, 397, 414, 419). The character emerges when a young man travelling alone enters a strange community. The traveller is warned that a man lives in the community who seeks out and attacks strangers, challenging them to a series of contests or duels. An alternate form of the stranger-killer is the monster, such as the "giant mouse" who attacks travellers along the Colville River (Ostermann and Holtved 1952:154). In most accounts, the young man escapes through his own quick thinking; in some cases, he receives advice or minimal protection from his affinal kinsmen. As a stranger is by definition anyone unrelated through kinship or partnership affiliation, the 
"man who always kills strangers" graphically portrays the helplessness of an individual outside the network of kinship ties.

Folktales use a high level of redundancy to communicate specific social values and relationships which reinforce the stability of the local group as the unit which endures seasonal food shortages. An individual cannot exist in the absence of social connections which provide both economic support and protection. Folktales also convey that the capacity of these units to buffer subsistence stress is spatially limited. The unenviable position of the stranger simultaneously demonstrates the necessity for membership in a social network, while emphasizing the normally restricted scope of those ties. The means for establishing a broader network of contacts, however, receives comparatively little attention in folktales.

Treatment of resource variability and human response. Both myths and folktales make limited but significant references to times of environmental stress. Two levels of hardship are distinguished: food shortages, which result in hunger, and actual famine, which results in starvation and death. The accounts consistently specify the degree of hardship, as well as the circumstances responsible for the hardship, and the appropriate response for survival.

In the present sample of myth and folktales, two accounts of famine are recorded. The first forms part of the creation myth of the Nunamiut and attributes the hardship to altered climatic conditions:

\footnotetext{
. . . toward the end of itchaq imma, the summers began to shorten. The sun could no longer melt the ice and snow. Ice started to grow and extended from high places in the mountains down into the valleys . . . As the weather grew colder, the Nunamiut experienced increasing difficulty in making a living (Gubser 1965:42).
}

The ice continued growing and filled all the major valleys of the Brooks Range. The glaciation did not extend all the way to the coast but did force the Nunamiut to leave the mountains. All the giant animals died because they had no place to live. The spruce gave way in front of the ice and cold. Many people died. Only those living on the coast where they could hunt sea animals managed to survive (Gubser 1965:42-43).

The creation myth makes four explicit statements on the nature of resource variability. ${ }^{11}$ First, the account attributes the diminishment of the inland faunal resource base to conditions of increasing cold. Second, the growth of spruce is referenced as an indicator of changed climatic conditions. During the preceding warm period, spruce was said to have flourished along the Colville and the trees were substantially larger in diameter at that time (Gubser 1965:34). One informant commented that he had seen spruce logs as "large as stove pipes" in the cutbanks of the Colville, a fact which he cited as evidence of the veracity of the climatic shift (Gubser 1965:33). Third, the myth possibly suggests the temporal scale of such regional crises by placing the event in the distant past. Finally, the 
myth specifies the appropriate response to a region-wide resource failure in the interior: to relocate to the coast and use marine mammals.

A second reference to famine, contained in the folktale of Alarana and her younger brother, also indicates that survival of widespread subsistence crises depends on emigration to the complementary resource zone:

Famine once came to Point Barrow and everybody died except a brother and sister, Alarana the girl and Aligunaluk her young brother. As no one was left alive, they left the place and began to wander inland in an attempt to reach the caribou hunters, who had travelled up the river Kulugjuaq (Ostermann and Holtved 1952:173).

The interdependency of resource zones receives more explicit treatment in the following folktale reference to starvation:

There lived a mother and son out by the point at tukut. He was a strong man who would take whales in his kayak. The inland people who hunted caribou came down and would trade their caribou skins for the blubber which the whaler had. When they traded, the whaler would examine the skins and take the best ones for himself. The inland people finally wanted to kill him. When he came to the inland people in his kayak, they stuffed the cockpit of the kayak with skins so that he couldn't free himself. Then they started throwing harpoons at him. He was able to kill some of them and threw stones at their umeak, making a hole in the bottom so that it sank. Then he kept them from reaching the shore. But some of them managed to spear him and kill him. After he was dead, they, having no blubber, starved (Spencer 1959:429).

The death of the family demonstrates the necessity for access to resources of another region. Apparently, even a greedy, unethical partner is better than no partner at all.

References to food shortages, as opposed to starvation, are more common, but are found only in folktales. In the majority of cases (6 of 9), the shortage is attributed to the naturally lean season of late winter and early spring. Generally, the shortage affects only part of the community (usually an orphan) and is brought on by the unwillingness of certain community members to share from their supply of stored meat.

The appropriate responses to seasonal food shortages reflect the use of local obligations for economic support. In three cases, the situation is alleviated through reliance on kinship ties. In two cases each, shortages are mediated through either the sharing of stored surpluses between families, the role of the umealiq in providing for less well-supplied members of the community, or magical assistance. In only one case, the orphans survive by relocating to another coastal community.

Comparison of myths and folktales. The differential treatment of survival information in myth and folktales can be further illustrated through a quantitative comparison of their content across six general areas, comprising the strategies and the social mechanisms for surviving seasonal shortages, interannual fluctuations, or long-term, regional crises (Table 
4). It was anticipated that if myth and folktales placed equal stress on these survival strategies of different time depths, then the strategies would receive an equal number of references in the oral literature.

In the present case, where the strategies are represented by an unequal number of themes, the expectation was that each strategy would be referenced in proportion to the number of individual themes included under that thematic heading. The observed frequency of mention for each thematic group was tabulated from the data summary in Table 6. The expected frequency was generated according to the proportion of the total number of themes falling in each of the six preceding categories, multiplied by the total number of thematic references recorded for either mythical or folktale accounts.

A $\chi^{2}$ test for goodness of fit between the observed and expected frequencies indicates that both myth and folktale treat the different classes of survival tactics in a preferential or non-uniform manner (Table 7). In the body of mythical accounts, strategies for surviving long-term crises (the-

TABLE 7

Differential. Treatment of Survival Information In Myth and Folktale

\begin{tabular}{|c|c|c|c|c|}
\hline $\begin{array}{l}\text { Thematic } \\
\text { group }\end{array}$ & $\begin{array}{l}\text { Expected } \\
\text { frequency }\end{array}$ & $\begin{array}{l}\text { Observed } \\
\text { frequency }\end{array}$ & $\begin{array}{c}\text { Contribution } \\
\text { to } \chi^{2}\end{array}$ & $\begin{array}{l}\text { Over }(+) / \text { under }(-) \\
\text { represented }\end{array}$ \\
\hline \multicolumn{5}{|c|}{ MYTH } \\
\hline 1 & 7.65 & 7 & .055 & \multirow{4}{*}{ - } \\
\hline 2 & 35.73 & 28 & 1.672 & \\
\hline 3 & 7.65 & 9 & .238 & \\
\hline 4 & 5.12 & 5 & .003 & \\
\hline 5 & 7.65 & 18 & 14.003 & \multirow[t]{2}{*}{+} \\
\hline \multirow[t]{2}{*}{6} & 10.20 & 7 & 1.004 & \\
\hline & \multicolumn{4}{|c|}{$\begin{aligned} 2^{2}(5 d f .05) & =\overline{16.975} \\
& =11.07\end{aligned}$} \\
\hline \multicolumn{5}{|c|}{ FOLKTALE } \\
\hline 1 & 53.35 & 50 & .210 & \multirow{3}{*}{+} \\
\hline 2 & 249.18 & 368 & 56.657 & \\
\hline 3 & 53.35 & 48 & .537 & \\
\hline 4 & 35.61 & 16 & 10.799 & - \\
\hline 5 & 53.35 & 13 & 30.518 & - \\
\hline \multirow[t]{3}{*}{6} & 71.16 & 21 & 35.357 & - \\
\hline & \multicolumn{4}{|c|}{$x^{2}=\overline{134.078}$} \\
\hline & & $x^{2}(5 d f .05)$ & $=11.07$ & \\
\hline
\end{tabular}

a Thematic groups: (1) Strategies for surviving seasonal shortages (themes 1-3). (2) Mechanisms for surviving seasonal shortages (themes 4-17). (3) Strategies for surviving inter-annual crises (themes 18-20). (4) Mechanisms for surviving inter-annual crises (themes 21-22). (5) Strategies for surviving long-term crises (themes 23-25). (6) Mechanisms for surviving long-term crises (themes 26-29). 
matic group 5) received substantial emphasis, while social mechanisms for buffering seasonal variability (thematic group 2 ) were significantly underrepresented. Conversely, folktales stressed the appropriate responses to seasonal shortages to the near exclusion of references to survival strategies relevant to interannual or long-term fluctuations (thematic groups 4 , 5 , and 6). The observed deviations from a uniform distribution were statistically significant at the .05 level for both myth and folktales.

In summary, although myths and folktales arc both forms of secular oral tradition, they appear to encode information concerning resource variability and survival strategies on two distinct spatial and temporal scales. Further, they use different means of tagging this information as important.

In folktales, times of hardship derive primarily from seasonal variability in resource availability and occur during the lean months of late winter and early spring. The alleviation of seasonal food shortages depends on an accentuation of those social values and relationships which support the pooling of labor and shared resources, i.e., kinship and intracommunity voluntary associations. Folktales rely on redundancy to hammer home the encoded message, a method which is sufficient for the short-time scale over which the information must be maintained.

Creation myths, in contrast, encode strategies for the survival of longterm, regional resource crises. Myth details the origin of institutions which provide social access to other regions in times of stress. Further, myth appears to communicate knowledge concerning the long-term nature of major resource fluctuations and the environmental conditions associated with crisis situations. In the interim between fluctuations, myth preserves this survival information by validating the account with historical time depth.

\section{Content of Sanctified Oral Traditions}

As an active performance, rituals and tabus communicate by providing a model, either through direct representation of social relations, or through symbolic reproduction of cosmological structure. The following content analysis of Tareumiut and Nunamiut rituals and tabus accordingly focuses on the sequence of sanctified actions and the verbalized understandings which motivate them. The social and cognitive structures which give coherence to these actions are then reconstructed. The survival value of the encoded information is evaluated through a comparison of the cognized model of the social and natural worlds with the operational model of resource variability and social buffers developed earlier.

The rituals and tabus of the spring hunt were motivated, as were all hunting practices, by the belief that animals have both individual and 
communal spirits, termed ilitqusiq and inua. which control the animals and determine man's hunting success. The ilitqusiq, or breath-spirit, consists of the spiritual counterpart of the individual animal, and is that entity which gives the animal breath or life (Marsh 1954:22-24; Rainey 1947:261; Rink 1875:36; Spencer 1959:291). Although invisible except to the shaman, the breath-spirit is envisaged as a vaporous image of the species which resides in a specific part of the animal's body, generally the head. If released from the body at death, the breath-spirit continues to exist and is the sentient life-force which reincarnates into another member of its species.

In contrast, the inua (pl. inue) comprises the "person, owner, or inhabitant" of a species, and in this context, is glossed as species-spirit (Marsh 1954:24; Rainey 1947:261; Rink 1875:37; Spencer 1959:266). ${ }^{12}$ In keeping with the concept of the animal's person, an inua frequently assumes human form. In ritual masks, the inua of a species is depicted as a small human face on the back or in the eye of a creature (Fitzhugh and Kaplan 1982:13); in oral accounts, an animal's inua discloses its presence when the animal pushes back the skin of its face (as if throwing back a parka hood), revealing the human form beneath. As the spiritual projection of an entire species, the inua stands in relation to all the individuals of that species as their omniscient guide and protector. ${ }^{13}$

Man's success in utilizing the animal world for his own survival depended on the quality of his interactions with these spirit beings. The breath-spirit had to be treated with respect, both in order to entice the spirit in its reincarnated form to return again to the same hunter, and so that the spirit would inform its fellow species members of the good treatment it had received (Spencer 1959:64). Similarly, as the omniscient inua could discern the affairs of man from afar, the proper ritual relations had to be established in advance, so that the inua would not warn its species members away from the path of the hunter (Gubser 1965:327-330).

Tareumiut rituals and tabus. Preparations for the spring whaling season began with the return of daylight in early March. During the initial preparatory phase, the men of the community were engaged in readying and assembling the whaling equipment. Every weapon, including the harpoons, lances, and floats, had to be carefully cleaned and prepared, and brought to the karigi. The women were involved in the related tasks of recovering the walrus-skin umiak or whaling boat, and making new clothing for the crew members.

The predominant theme dictating the preparatory actions was that contamination through contact with previous hunting expeditions, particularly of land fauna, was offensive to the whale. Strict tabus on the mixing of land and sea were accordingly initiated during this period, and continued throughout the spring hunt. This prohibition generated the obliga- 
tion to cleanse all whaling equipment of contact with land fauna, as well as the wearing of new clothes which had not been worn previously in hunting. The bones of any land animals taken during the previous fall and winter which remained in the community were removed to the ice edge and burned. Restrictions on eating inland fauna, such as caribou and fish, were also observed.

The second phase of preparation began in mid-April. At this time, the men of the crew put on the new clothing and retired to the karigi for 4 days. This was a time of great solemnity, and no levity or sexual relations were permitted. The crew members were expected to sit quietly and think of whales, or to instruct the younger crew members in the art of whaling. The shaman or spiritual advisor meanwhile sang special songs to attract the whales.

The umealiq had a different set of obligations to fulfill at this time. It was essential that the umealiq have his ice cellars cleaned of meat, particularly that of any whales previously taken. The surplus of frozen meat from the umealiq's store was first distributed among the wives of his crew members and then among the larger community. The wife of the umealiq was engaged in the parallel task of cooking all leftover muktuk or whale skin, and distributing it as well to community members.

At the end of the 4-day period, the final phase of preparation was marked by a ritual bath. If a crew member had recently hunted caribou or land fauna, it was necessary that the essence of the animal which still clung to him be removed by washing. The crew then departed to set up the whaling camp out on the ice near the leads. All whaling gear was loaded into the umiak and the boat was pulled to the edge of the ice. Some distance from the lead, the men got into the boat, still resting on the ice, and began to enact the whale hunt. The camp was then established and the period of waiting began. No tents or fires were allowed on the ice; the crew's attention was redirected from creature comforts to the importance of the work at hand. Personal and group food tabus remained in effect.

During this period of waiting, the activities of the women were similarly restricted. The wife of the umealiq, in particular, was to sit quietly at home, refraining from work of any kind, lest the whale be made harder to catch. The wives of the other crew members could not sew, so that the whale would not foul the lines and escape. The entire community was prohibited from making noise, such as chopping wood or clapping hands, as such noises were said to frighten off the whales.

The second stage of the whaling ritual, that of welcoming the whale, followed immediately after the whale had been taken and dragged up on the ice. The umealiq's wife was summoned from her house, and taking a seal flipper pouch of fresh water, she joined the crew on the ice to bestow 
the formal greeting. First, the head of the carcass, containing the animal's breath-spirit, was severed from the body and set upright on the ice. The wife of the umealiq then poured the fresh water over the animal's nose and blowhole, and addressed the whale's spirit saying, "It is good that you are come to us." The umealig repeated the action, affirming, "Here is water, you will want to drink. Next spring come back to our boat" (Spencer 1959:345).

The whale, now formally welcomed into the community, was ready for butchering. The muktuk or skin was first removed and distributed to all present as a reflection of the crew's generosity. The carcass was then divided by the women, while the men returned to their posts on the edge of the ice. As soon as the butchering was complete, the head of the whale was returned to the sea, accompanied by the shout, "Come back next year!" This released the breath-spirit and enabled it to reincarnate (Lowenstein 1981:60-61; Rainey 1947:261). With each whale taken, the same procedure of ritual greeting was followed.

The return of the boats to land signalled the official end of the whaling season. At that time, the successful umealiq hosted the qagruq celebration, a communal feast consisting of the whale flippers and fermented whale meat, and the subsequent "blanket toss" (nalukataq) celebration. Although the festivities marking the close of the whaling season appear more social than ceremonial, the communal feasting, dancing, and games received supernatural sanction, in that the object was to inform the whale of the community's happiness and gratitude (Milan 1964; Spencer 1959).

Nunamiut ritual and tabus. The ritual actions associated with the spring caribou drives differ from those of the coast in degree rather than in kind. Preparation for the caribou drive began in late March with the return of the hunting crew members to the traditional hunting grounds and with the establishment of temporary hunting camps in strategic locations. Most activity during this first stage was oriented toward the construction or repair of the drive corral under the direction of the umealiq, and the building of a temporary karigi structure. While these activities went on, the shaman would search for caribou tracks and droppings, and sing over them to compel the caribou to come.

As on the coast, preparations for the spring hunt were motivated by the belief that the association of land and sea elements was offensive to the animal's soul, and tabus governing the separation of marine and terrestrial fauna went into effect at this time. All weapons had to be washed and scraped clean of contamination from other fauna and assembled in the karigi. New clothing completely of caribou skins was necessary for the hunt.

In the second stage of preparation, the men retired to the karigi structure for 4 days. During this time, the men were to think of caribou and to 
avoid sexual intercourse, as this was also offensive to the caribou. The shaman sang over the assembled weapons and drummed so that the caribou would come submissively. Scouts were sent out to locate the migrating herds, and on the fourth day, the men departed for the hunt.

While the men were waiting to make contact with the herd, the rest of the community was obligated to observe certain tabus on activities. The making of cordage, cutting with a knife, and sewing were forbidden, so that the caribou would not escape. Similarly, there could be no loud noises in the camp, lest the caribou hear them from afar.

After the caribou had been driven into the corral and slaughtered, the hunters performed the second stage of the ritual process, that of the ritual greeting. First, the heads of the caribou were cut off to release the animals' souls. As each head was severed, the cutter called out to the departing spirit, "Come back to us again." The heads were then placed to one side and the carcasses butchered. Additional ritual treatment of the animal involved cutting the skin of the fetlocks and burying small pieces in the ground or snow (Porter 1893:140), or rubbing the hooves of the animal with blubber (Stefansson 1919:389).

The final phase of ritual surrounding the caribou drive came at the close of the spring hunting season. Social festivities marked by dances, games, and the display and distribution of meat were followed by a closing ceremony thanking the caribou. The severed heads were addressed by the umealiq and the shaman, who jointly gave a message of gratitude to the animals' spirits and an invitation to return.

The information content of hunting rituals and tabus. Previous analyses of Tareumiut and Nunamiut hunting rituals and tabus have focused on the indexical information conveyed by these communal rites and accordingly have stressed the role that these rituals perform in signalling and establishing non-kin solidarity and group cohesion (Lowenstein 1981:66-67; Mauss 1979; Spencer 1959). A number of elements in the performance support this interpretation. First, the emphasis on the hunting crew and the karigi association as the unit of ritual activity signals at the indexical level the interdependency of the crew at the subsistence level. The coordination of the wives of the crew members on such tasks as recovering the whaling boats, the sewing of new clothes, and the greeting of the animals functioned to further bridge the bounds of the nuclear family for the good of the larger unit.

Similarly, the posthunt celebratory distribution of meat between crews both represents and creates patterns of obligatory reciprocity throughout the community distinct from those patterns established on the basis of kinship, while signalling the protective and leadership role of the umealiq in the community. Finally, the ritual welcome of the animal not only involves the entire human community, it incorporates the animal into that 
community through the formal greeting process (Spencer 1959:345). Only when the animal has been initiated as a member of the community does it have subsistence utility. At the indexical level, the spring hunting rituals both communicate the collective nature of subsistence practices and provide an appropriate sanctified context for the annual renewal of group solidarity and economic integration.

A second, canonical level of meaning, however, is also conveyed through the invariant and symbolic aspects of hunting rituals and tabus which reflects indigenous beliefs concerning the structure of the natural environment. At the apex of this structure is the belief that the animal world is animated by sentient spirit-beings (breath-spirits and speciesspirits), which control the behavior of corporeal, physical animals. In attempting to gain control over physical animals through their spiritual counterparts, man's ritual interactions with the animal spirit-beings provide a cognized model of those factors which determine the nature and availability of faunal species as subsistence resources.

Two phases of the hunting ritual attempt to manipulate the compliance of the spirit-beings: the preparatory activities designed to reassure the animal's inua of a proper reception, and the postkill observances marking the correct treatment of the breath-spirit. In both phases, positive relations were established through respectful treatment of the animals' spirits. However, what was considered respectful in each of these contexts contrasts, and provides two complementary statements concerning the nature of faunal resources.

During the ritual preparations for the spring hunt, respect for the animals' inue was demonstrated through ritual cleanliness, consisting of the complete separation of land and sea. In preparation for the spring whaling season on the coast, weapons had to be cleaned of previous contact with land fauna; clothes which had been worn on other hunts could not be used and new clothes had to be made. No deerskins could be sewed or mended after the return of light in early March, although sealskins could be worked (Stefansson 1919:353). During the caribou drive, similar prohibitions on contamination with marine fauna required the sewing of new clothes of inland skins, and the cleansing of hunting implements.

While the spring hunt intensified the concern for ritual cleanliness, many tabus regarding the separation of land and sea were in effect year round. For both coastal and inland groups, food tabus prohibited the cooking of terrestrial and marine fauna in the same pot, or the eating of meat or oil from the land and sea on the same day (Stefansson 1919:322), or if on the same day, at different times and the partaker should wash his hands between courses (Spencer 1959:265). A woman should not scrape or sew caribou skins near a whaling station nor should she sew caribou skins while there was a seal in the house which was not yet dismembered 
(Stefansson 1919:353). A caribou spear should not be used to kill seals, nor should a seal harpoon be used to dispatch snared caribou (Gubser 1965:326).

Prior to the hunt, respect for the animals' inue was synonymous with the ritual separation of land fauna from marine fauna. Through the consistent division of land and sea in food, equipment, clothing, and hunting activities, the rituals and tabus provide a performative model of the organization of the natural world which stresses the inherent dichotomy between marine and terrestrial resources.

After the kill, the definition of respect for the animal's spirit-beings took on a second meaning, that of honoring specific wishes of the animal's breath-spirit. Animals allow themselves to be killed by a hunter because they want something from man. If these needs were met, the spirit would then return and "bring the good news" to its fellow species members (Gubser 1965:326). The ritual observed after the kill assured first that the animal's spirit was released from the body, and second, that the specific wishes of the spirit were satisfied. In contrast to the preparatory rituals and tabus, the specific needs symbolized by the postkill ritual recognize the essential equivalency underlying the apparent duality of terrestrial and marine resources.

A major feature of the spring whaling ritual consisted of greeting the whale with fresh water. This ritual greeting follows the more general pattern of giving a drink of water to sea mammals on being brought to shore. The immediate motivation for this action is to refresh the thirsty soul:

It is said that no animals (sea mammals) would allow themselves to be caught by man were it not for their thirst; they had no fresh water to drink where they lived in the sea. For this reason a seal was given water when brought into the house. Beluga and balaena were given water on being brought to shore. It is generally the wife who gives the seal water. . . . As she does this she says: so that you may keep getting water to drink, come again; water is not a thing grudged you (you will not find need to beg for the water you get). The soul of a seal thus treated will be grateful and when it has again become a seal it will allow itself to be caught by the same man, partly through gratitude, partly because it knows that at his house it is sure of a drink of fresh water (Stefansson 1919:351; emphasis added).

The primary concern was that the water was fresh, i.e., it could not be from the sea.

A related set of practices governed the treatment of killed caribou and land animals. Proper ritual treatment of caribou dictated that the head of the animal must be completely severed from the body. While this act functioned, on one hand, to release the animal's spirit, the cutting additionally satisfied the desire of land animals for a knife or to "feel the knife of a good hunter at its throat" (Gubser 1965:273; Milan 1964:32). Cutting the skin around the fetlocks may have served a comparable purpose. 
A distinct pattern of ritual treatment of caribou emerges in coastal communities. Among the Tareumiut, proper greeting of the caribou required that the hunter rub blubber on the caribou's hooves and put small pieces of blubber or a few drops of oil into the animal's ears (Stefansson 1919:398). Although no reason for this treatment is mentioned, in keeping with the larger pattern of gratifying the spirit's desires, the act suggests recognition of a craving on the part of caribou for products from the sea.

The apparently contradictory desires for elements outside the animal's physical environment reflect the spiritual origin of the animal. During its lifetime, every animal has a spirit (taktok) which is its double in the complementary resource zone. Killer whales are the taktoit of wolves, bowhead whales are the spirit doubles of muskoxen, mountain sheep have as their taktoit beluga whales, while caribou double as small humpback whales (Jenness 1953:8; Nelson 1899:444; Spencer 1959:266-267; Stefansson 1919:357).

The paired animals are said to be avariksut, i.e., "chips off the same block," equivalent, alike, or equal (Stefansson 1919:319), and the pairing of species matches similarities in behavior or appearance. Killer whales surround and attack their prey in the manner of wolves; bowhead whales are large and slow moving as are muskoxen. Both beluga (white) whales and mountain sheep are white in color and timid in character. Caribou and humpback whales may be related through the association of the whale's hump with the withers of the caribou, as well as through their smaller size and darker color.

The relationship between the paired species is not restricted to a static association, however. When wolves starve on land they go to their relatives in the sea and turn into killer whales; conversely, killer whales, when unable to find food in the sea go inland and become wolves (Stefansson 1919:319). Caribou have been known to leap into the sea and swim away as humpback whales in order to avoid pursuit on land (Spencer 1959:267). Similarly, mountain sheep often wander down to the sea and become beluga. Hence when there are plenty of beluga off the Arctic coast, mountain sheep will be scarce; when sheep are plentiful in the Brooks Range, beluga are absent in the adjacent coastal regions (Jenness 1953:8).

The thirst of the whale or seal now becomes interpretable: it is the taktok of a land animal residing in the body of a marine mammal which is thirsty. Supplying the caribou with blubber and seal oil recognizes the marine animal spirit in terrestrial form. In acknowledging their alternative spiritual identity, the ritual greeting of the animal's spirit effects a mediation of the physical opposition of land and sea.

Hunting rituals and tabus provide a model of the structure of faunal resources which balances the spatial dichotomy of resource zones against 
the alternate temporal availability of their fauna. The preparatory rituals and tabus stress the spatial duality of marine and terrestrial resource zones through the consistent physical separation of their faunal products. On one level, this sanctified separation forces an awareness of the potential of the alternative resource zone at the time when the group is most intensively involved in the specialized use of its own resource base.

In contrast, the postkill ritual greeting, by confirming the true spiritual identity of the animal, provides a model of the equivalent resource potential and alternative temporal availability of marine and terrestrial fauna. When marine mammals are not found in the sea, they are with their spiritual doubles on the land, and vice versa. Further, the cognized model encodes an explicit example for appropriate human response to resource failure. Just as fauna may adopt an alternative form and move between resource zones in times of need, human hunters should emigrate and adopt an alternative subsistence orientation when local resources fail.

At the indexical level, then, the spring hunting rituals create a sanctified context for the confirmation of group cohesion and economic interdependency. In supporting the local social unit, communal rituals facilitate the strategies of specialization and storage which maintain the group across seasonal and short-term subsistence crises. At the canonical level, the rituals and tabus provide a cognized model which establishes marine and terrestrial fauna as spatially distinct but alternately available resources. In encoding information concerning the resource potential of the alternative resource zone and the necessity for interhabitat zone movement in times of stress, the rituals transmit strategies for surviving longterm, regional resource failures.

\section{THE SURVIVAL VALUE OF ORAL TRADITION}

The preliminary model of oral tradition as a cultural mechanism for the storage and retrieval of survival information can be evaluated at this time. At the most general level, the model argued that the survival of human populations across critical fluctuations in their resource base is largely dependent on a group memory of past crisis situations and of the strategies appropriate for dealing with the altered environmental conditions. This group memory functions as a body of reference knowledge from which decisions on alternative survival strategies can be formulated in times of subsistence stress. The model further suggested that one mechanism utilized by nonliterate societies for the perpetuation of reference knowledge through time is through its incorporation in the various oral traditions of the cultural group. 
At a more specific level, the model stated that the suitability of an oral medium for transmitting information relevant to subsistence crises of varying periodicity and severity is determined by its social context which specifies the potential longevity and social cost of information transmission. Two contrastive types of social contexts were proposed. Secular oral traditions entail little social cost but depend on repetition for perpetuation with inherent possibilities for distortion. Sanctified oral traditions, such as ritual performances, involve considerable outlay of time and energy but assume an invariant character necessary for the transmission of survival information over extended periods of time. Balancing the social cost of information transmission against the severity of a perturbation, and accuracy against temporal scale, the model predicted that secular oral traditions would encode information relevant to short-term fluctuations of lesser magnitude, while sanctified oral traditions would transmit survival information over the long term between resource fluctuations of greater magnitude.

The traditional Tareumiut and Nunamiut hunting peoples demonstrate a clear cultural cognizance of the memory function performed by oral tradition. Various oral media were consulted in times of stress as a source of survival information which had been preserved against future disaster.

As a body of reference knowledge, the oral traditions of the Tareumiut and Nunamiut transmit survival strategies relevant to three scales of severity in subsistence stress: (1) seasonal shortages created by the migratory movements of the primary faunal species; (2) localized, short-term crises brought on by shifts in the migration path of the caribou or adverse whaling conditions; and (3) long-term (pan-generational), regional crises associated with variability in large-scale weather patterns, which alternately favored the availability of either coastal or interior resources.

The fictional accounts of folktales provide only minor constraints on the accuracy of transmission and these tales encode information of little time depth. Folktales contain references to seasonal hardship, and specify a reliance on the pooling of resources between local social units as a means of mediating the crisis situation. The repetitive device of stereotypic characters endorses specific social values and economic obligations which reinforce the interdependency of the local group as the unit which endures seasonal food shortages.

The cultural value placed on historicity engenders an increased concern for accurate transmission and ensures the greater longevity of information encoded in myth. Mythical accounts record cases of severe hardship, including starvation and famine associated with resource failure occurring at less frequent intervals. Myth encodes strategies for the survival of local or widespread resource failure in two ways: by illustrating the relocation of the population relative to available resources, or 
by detailing the origins of social alliances which provide access to the resources of other territories or regions.

Hunting rituals and tabus utilize a supernatural sanction and the threat of starvation as strong incentives for the accurate reproduction of ritual performances and of encoded information over a greater span of time. Although rituals and tabus contain no direct references to hardship, these media reproduce a cognized model of the natural world which stresses the alternate temporal availability of spatially distinct zones of inland and coastal resources. Knowledge of the recurrent nature of major resource fluctuations and the potential of adjacent resource zones becomes critical for the survival of long-term, regional resource failure.

For the Tareumiut and Nunamiut, survival of subsistence crises depended on a knowledge of alternative resources or the appropriate means for dealing with the altered conditions. As a body of reference knowledge, oral tradition clearly provided one enduring means for the preservation of hard-won survival experience between occurrences of resource crises.

\section{ACKNOWLEDGMENTS}

I thank Robert Whallon, John Speth, John O'Shea, Joyce Marcus, Jeffrey Parsons, and Sergei Kan for the discussions and encouragement that assisted in the development of the ideas presented in this study. Kevin Smith was particularly helpful as a consultant and guide to the arctic literature. The original draft of the paper benefitted greatly from their time, comments, and suggestions. In addition, I thank the anonymous reviewers for their detailed and constructive criticisms on both the substance of the paper and my prose style. Although I was unable to respond to all of their suggestions in the present version, their insights have proved stimulating and will hopefully bear fruit in further work on this problem. Finally, I thank Dennis Albert for his generous assistance in editing and proofreading various drafts as well as the final copy.

\section{NOTES}

${ }^{1}$ There is a density-dependent relationship between the frequency of range shifts and population size. Under high densities, herds graze a given range for shorter periods of time, and demonstrate more frequent range shifts and movement over larger areas. Under low densities, herds shift grazing grounds less frequently and within a more restricted region associated with the traditional calving ground. As a result, there is an apparent inverse relationship between overall abundance of the species, and the predictability of herd movement and location.

2 "Catch," as used here, refers to the number of whales successfully landed, and does not include those animals struck but lost.

${ }^{3}$ The 1963 weather values reflect one of the worst storms in the recorded history of the area, resulting in record high winds and an unusually ice free ocean (Hume 1965).

4 March and June immediately precede and follow the peak of the whale hunt; accordingly, their strong relationship to whaling success may be less one of direct causality, than as sensitive indicators of seasonal weather conditions. 
${ }^{5}$ Factors contributing to postglacial changes in sea level remain to be determined; however, Stanford (1976) suggests a correlation with climatic fluctuations based on data presented by Bryson and Wendland (1967).

${ }^{6}$ According to Rainey (1947:261), however, older whalers at Point Hope reminisced about seasons in which the whales were so numerous that "hunters pursued only the young ones and merely threw ice at the older and larger whales to drive them away," suggesting that after an especially good harvest (15 to 18 whales), serious whaling efforts were reduced.

${ }^{7}$ Wealthy men (umealit) could and did maintain a broader range of partnerships than did the average hunter (Hennigh 1983), a factor which increased their level of social responsibility as well as their own chances for survival in times of subsistence stress.

${ }^{8}$ The ethic of respect, however, was at least partially open to individual interpretation. The spiritual advisor of the crew took an active part in decreeing, according to experience and inspiration, a supplementary set of tabus which were binding only for his crew for the duration of that season's hunt. These tabus constituted additions to, not major modifications of, the core ritual actions.

${ }^{9}$ The following myth and folktale accounts were analyzed.

I. Nunamiut accounts:

(1) Aiyagomahala and the Creation of the Nunamiut (Gubser 1965:29-32);

(2) "Some time during this warm period, a gigantic earthquake ..." (Gubser 1965:34-35);

(3) Mr. Raven Brings Light to the People (Gubser 1965:35-39);

(4) Kayaktuaguniktuu (Gubser1965:39-42);

(5) "Some time after Kayaktuaguniktuu . . . " (Gubser 1965:42-43);

(6) The Story of Ikiashuruak and the Caribou (Gubser 1965:327-332);

(7) 6. The Imprisoned Children (Jenness 1926:33-34);

(8) 7. The Castaway (Jenness 1926:34-35):

(9) 8. The Abused Orphan (Jenness 1926:35-36);

(10) 9. The Orphan's Gratitude (Jenness 1926:36-38);

(11) The Sacred Gift of Song, Dance and Festivity (Ostermann and Holtved 1952:38-42);

(12) The World's Islands Become Mainland* (Ostermann and Holtved 1952:151, cf. No. 20);

(13) The origin of Little and Big Diomede Islands: "There was once a young man who had caught a baby seal . . ." (Ostermann and Holtved 1952:152);

(14) The Giant Mouse of Colville River and the Two Brothers who Killed It (Ostermann and Holtved 1952:154-157);

(15) The Raven who Married the Arrogant Girl who Refused Men (Ostermann and Holtved 1952:157-159);

(16) The Chief's Son who Married a Brown Bear (Ostermann and Holtved 1952:159-164);

(17) Iraq, the Baby who Ate its Parents and then the Whole Settlement (Ostermann and Holtved 1952:164-165);

(18) The First Two Shamans who Came From the Sky (Ostermann and Holtved 1952:165-167);

(19) Tulugaluit - A Raven Family (Ostermann and Holtved 1952:167-168);

(20) Whale Bones in the Interior (Ostermann and Holtved 1952:168-169);

(21) The Eagle Who Abducted the Head Man's Daughter (Ostermann and Holtved 1952:169-171);

(22) The Girl Alarana and her Brother who were Eaten by Wolves and Afterwards became Caribou (Ostermann and Holtved 1952:173-179). 
II. Tareumiut accounts:

(23) 1. The Orphan Boy (Jenness 1926:32);

(24) 10. The Wolf's Bride (Jenness 1926:38-42);

(25) 34. The Woman and her Grandfather's Skull (Jenness 1926:64-65);

(26) 35. The Stone Baby (Jenness 1926:65-66);

(27) 36. The Giants (Jenness 1926:66-67);

(28) 41. The Orphan Who Was Drowned (Jenness 1926:69-70);

(29) The Myth of the Whale (Ostermann and Holtved 1952:24, cf. The Raven in the Belly of a Whale, p. 172);

(30) A Very Dangerous Hunting Trip (Ostermann and Holtved 1952:216-222);

(31) Apakieq who Perished in a Kayak and Returned to Mankind Again (Ostermann and Holtved 1952:222-223);

(32) A Moral: Qilangatsiaq, the Living Drum (Ostermann and Holtved 1952:223224);

(33) Qilangatsiaq (Ostermann and Holtved 1952:225);

(34) When Tikeraq Was Harpooned* (Ostermann and Holtved 1952:225-226, cf. No. 36);

(35) How the Spider Came (Ostermann and Holtved 1952:226-228);

(36) The Creation (Spencer 1959:384-385);

(37) The Origin of Light* (Spencer 1959:385-386, cf. No. 36);

(38) The Magic Lamp (Spencer 1959:386);

(39) The Spider (Spencer 1959:386);

(40) Nakkayaq and his Sister (Spencer 1959:387);

(41) The Headband (Spencer 1959:388-390);

(42) The Wolf Boy (Spencer 1959:391);

(43) The Story of Qaaweiluq (Spencer 1959:391-395);

(44) Kayaktuq, the Red Fox (Spencer 1959:395-396);

(45) The Blind Man and the Loon (Spencer 1959:396-397);

(46) The Tale of Maxwonaw (Spencer 1959:397-401);

(47) The Giant (Spencer 1959:402);

(48) The Poor Boy and the Two Umealit (Spencer 1959:402-413);

(49) The Woman Who Mistreated Caribou (Spencer 1959:413-414);

(50) The Worm (Spencer 1959:414-417);

(51) The Dog Wife (Spencer 1959:418-419);

(52) The Man Who Married the Polar Bear Woman (Spencer 1959:419-425);

(53) The Kukuweaq (Ten-Legged Polar Bear) (Spencer 1959:425-426);

(54) Text I. (Spencer 1959:428);

(55) Text II. (Spencer 1959:428-429);

(56) 1. How People Were Made (Murdoch 1886:594-595);

(57) 3. The Origin of Reindeer and Fishes (Murdoch 1886:595);

(58) 5. The Story of Kokpausina* (Murdoch 1886:596, cf. No. 47).

Accounts marked with asterisks were considered redundant and not included in the quantitative analysis.

$10 \mathrm{~A}$ copy of the annotated synopses of myth and folktale accounts is included in the original manuscript filed with the Department of Anthropology, University of Michigan, Ann Arbor, Mich. 48109.

11 Numerous small glaciers exist today in the higher elevations of the Brooks Range, and there is widespread evidence of neoglacial advances in this region during the Little Ice Age of the 16th, 17th and 18th centuries AD (Hamilton and Porter 1975; Pewe 1975; Porter and Denton 1967). Glacial activity has therefore occurred within the feasible time span of group 
memory, and familiarity with glacial advances on the part of the native population should not surprise us. We cannot, however, exclude the possibility that the explicit references in native accounts to massive glaciation and its effects on local flora and fauna reflect either the incorporation into traditional accounts of the results of earlier glacial and dendrochronological investigations (e.g., Giddings 1941; Solecki 1951), or the rephrasing of native concepts into scientific terms by the ethnographer.

12 Natural phenomena such as mountains, fire, lightning, thunder, etc., also were conceived of as having inue (Rink 1875:37), and in these cases the gloss of "species-spirit" is clearly inappropriate.

${ }^{13}$ The idea of protectress is especially well developed in the Sedna myth of the Bering Straits (Fienup-Riordan 1983).

\section{REFERENCES CITED}

Ahmadjian, V.

1967 The lichen symbiosis. Blaisdell, Waltham, Mass.

Aigner, J. S.

1982 Cyclicity in caribou populations and prehistoric archaeology on the North Slope interior of Alaska. Paper presented at the Symposium of North Slope Archaeology, Annual Meeting of the Society for American Archaeology, April. 1982, Minneapolis, Minn.

Allen, P. W., and R. O. Weedfall

1966 Weather and climate. In Environment of the Cape Thompson region, Alaska, edited by N. J. Wilimovsky and J. N. Wolfe, pp. 9-44. U.S. Atomic Energy Commission. U.S. Government Printing Office, Washington, D.C.

Amsden, C. W.

1977 A quantitative analysis of Nunamiut Eskimo settlement dynamics: 1898-1969. Ph.D. thesis, University of New Mexico, Albuquerque.

Baker, R. R.

1978 The evolutionary ecology of animal migration. Holmes \& Meier, New York.

Barnett, D. G.

1976 Long-range ice forecasting for Alaska's North Coast. Sea Technology 17(7):2427.

Barry, R. C., and R. J. Chorley

1982 Atmosphere, weather and climate (fourth ed.) Methuen, London.

Binford, L. R.

1978 Nunamiut ethnoarchaeology. Academic Press, New York.

1983 In pursuit of the past: Decoding the archaeological record. Thames \& Hudson, New York.

Bishop, C. A.

1978 Cultural and biological adaptations to deprivation: The northern Ojibwa case. In Extinction and survival in human populations, edited by C. D. Laughlin and

Bliss, L. C.

I. A. Brady, pp. 208-230. Columbia Univ. Press, New York.

1971 Arctic and alpine plant life cycles. Annual Review of Ecology and Systematics 2:405-438.

Bockstoce, J.

1980 The consumption of caribou by whalemen at Herschel Island, Yukon Territory, 1890 to 1908. Arctic and Alpine Research 12:381-384.

Braham, H. W., M. A. Fraker, and B. D. Krogman

1980 Spring migration of the western Arctic population of bowhead whales. Marine Fisheries Review 42(9-10):36-46. 
Breiwick, J. M., E. D. Mitchell, and D. G. Chapman

1981 Estimated initial population size of the Bering Sea stock of bowhead whale, Balaena mysticetus: An iterative method. Fishery Bulletin 78:843-853.

Brown, J., P. C. Miller, L. L. Tiezen, and F. L. Bunnell

1980 An Arctic ecosystem: The coastal tundra at Barrow, Alaska. Dowden, Hutchinson, \& Ross, Stroudsburg, Pa.

Bryson, R. A., and W. A. Wendland

1967 Tentative climatic patterns for some late glacial and post-glacial episodes in central North America. In Life, Land and Water, edited by W. J. Mayer-Oakes, pp. 271-298. Univ. of Manitoba Press, Winnipeg.

Burch, E. S., Jr.

1970 The Eskimo trading partnership in North Alaska: A study in balanced reciprocity. Anthropological Papers of the University of Alaska 15:49-80.

1972 The caribou/wild reindeer as a human resource. American Antiquity 37:339368.

1975 Eskimo kinsmen: Changing family relationships in northwest Alaska. American Ethnological Society Monograph 59. West, New York.

1981 The traditional Eskimo hunters of Point Hope, Alaska: 1800-1875. North Slope Borough.

Burch, E. S., and T. C. Correll

1972 Alliance and conflict: Inter-regional alliance in north Alaska. In Alliance in Eskimo society, edited by L. Guemple, pp. 17-39. Proceedings of the American Ethnological Society, 1971, Supplement. Univ. of Washington Press, Seattle.

Carroll, G. M., and J. R. Smithhisler

1980 Observations of bowhead whales during spring migration. Marine Fisheries Review 42(9-10):80-85.

Colby, B. N., G. A. Collier, and S. K. Postal

1963 Comparison of themes in folktales by the general inquirer system. Journal of American Folk-Lore 76(302):318-23.

Colson, E.

1979 In good years and in bad: Food strategies of self-reliant societies. Journal of Anthropological Research 35:18-29.

Cove, J. J.

1978 Survival or extinction: Reflections on the problem of famine in Tsimshian and Kaguru mythology. In Extinction and survival in human populations, edited C. D. Laughlin and I. A. Brady, pp. 231-244. Columbia Univ. Press, New York.

Cropper, J. P.

1982 Climate reconstructions (1801 to 1938) inferred from tree-ring width chronologies of the North American arctic. Alpine and Arctic Research 14:223-241.

Cropper, J. P., and H. C. Fritts

1981 Tree-ring width chronologies from the North American arctic. Arctic and Alpine Research 13:245-260.

Davis, J. L., P. Valkenburg, and H. Reynolds

Population dynamics of Alaska's western arctic caribou herd. Proceedings of the Second International Reindeer and Caribou Symposium, September 1979, Røros, Norway, in press.

Eckert, P., and R. Newmark

1980 Central Eskimo song duels: A contextual analysis of ritual ambiguity. Ethnology 19:191-211.

Fienup-Riordan, A.

1983 The Nelson Island Eskimo: Social structure and ritual distribution. Alaska Pacific Univ. Press, Anchorage. 
Fitzhugh, W. W., and S. A. Kaplan

1982 Inua: Spirit world of the Bering Sea Eskimo. Smithsonian Institution Press, Washington, D.C.

Flannery, K. V.

1972 The cultural evolution of civilizations. Annual Review of Ecology and Systematics 3:399-426.

Foote, D. C., and H. A. Williamson

1966 A human geographic study. In Environment of the Cape Thompson region, Alaska, edited by N. J. Wilimovsky and J. N. Wolfe, pp. 1041-1108. U.S. Atomic Energy Commission. U.S. Government Printing Office, Washington, D.C.

Fritts, H. C., T. J. Blasing, B. P. Hayden, and J. E. Kutzbach

1971 Multivariate techniques for specifying tree-growth and climate relationships and for reconstructing anomalies in paleoclimate. Journal of Applied Meteorology 10:844-864.

Garfinkel, H. L., and L. H. Brubaker

1980 Modern climate-tree growth relationships and climate reconstruction in sub-

Gaskin, D. E. arctic Alaska. Nature (London) 286:872-874.

1982 The ecology of whales and dolphins. Exeter, London.

Giddings, J. L., Jr.

1941 Dendrochronology in northern Alaska. University of Arizona Bulletin 12(4). Laboratory of Tree-Ring Research Bulletin 1.

Gubser, N. J.

1965 The Nunamiut Eskimo: Hunters of caribou. Yale Univ. Press, New Haven, Conn.

Hale, M. E., Jr.

1967 The biology of lichens. Arnold, London.

Hall, E. S., Jr.

1975 The Eskimo storyteller: Folktales from Noatak. Alaska. Univ. of Tennessee Press, Knoxville.

Halstead, P., J. O'Shea, and T. Whitelow

1984 Symposium on cultural responses to risk and uncertainty. Theoretical Archaeology Group (TAG), December, 1984, Cambridge.

Hamilton, T. D., and S. C. Porter

1975 Itkillik glaciation in the Brooks Range, northern Alaska. Quaternary Research 5:471-497.

Haugen, R. K., and J. Brown

1980 Coastal-inland distributions of summer air temperature and precipitation in northern Alaska. Alpine and Arctic Research 12:403-412.

Hemming, J. E.

1971 The distributional movement patterns of caribou in Alaska. Wildlife Technical Bulletin 1, Alaska Department of Fish and Game.

1975 Population growth and movement patterns of the Nelchina caribou herd. Proceedings of the First International Reindeer and Caribou Symposium. Biolog-

Hennigh, L. ical Papers of the University of Alaska, Special Report 1:162-169.

1983 North Alaska Eskimo alliance structure. Arctic Anthropology 20:23-32.

Hughes, R. C.

1974 Proposed Noatak National Arctic Range, Alaska: Final environmental statement. Alaska Planning Group, U.S. Department of the Interior. 
Hume, J. D.

1965 Sea-level changes during the last 2000 years at Point Barrow, Alaska. Science (Washington, D.C.) 150:1165-1166.

Inglis, J. T.

1975 The impact of reindeer grazing on selected areas of winter range in successive years, MacKenzie Delta area, N.W.T., Canada. Proceedings of the First International Reindeer and Caribou Symposium. Biological Papers of the University

Ito, $\mathrm{Y}$. of Alaska, Special Report 1:335-341.

1980 Comparative ecology. Cambridge Univ. Press, Cambridge.

Jacoby, G. C., and E. R. Cook

1981 Past temperature variations inferred from a 400-year tree-ring chronology from Yukon Territory, Canada. Arctic and Alpine Reseurch 13:409-418.

Jenness, D.

1926 Eskimo folk-lore. Report of the Canadian Arctic Expedition 1913-18, Vol. 13. F. A. Acland. Ottawa.

1953 Stray notes on the Eskimo of arctic Alaska. Anthropological Papers of the University of Alaska 1:5-13.

Jochim, M. A.

1976 Hunter-gatherer subsistence and settlement: A predictive model. Academic Press, New York.

1981 Strategies for survival: Cultural behavior in an ecological context. Academic Press, New York.

Kay, P. A.

1978 Dendroecology in Canada's forest-tundra transition zone. Arctic and Alpine Research 10(1):133-138.

Keene, A. S.

1981 Optimal foraging in a nonmarginal environment: A model of prehistoric subsistence strategies in Michigan. In Hunter-gatherer foraging strategies, edited by B. Winterhalder and E. A. Smith, pp. 171-193. Univ. of Chicago Press, Chicago.

Kelsall, J. P.

1968 The migratory barren-ground caribou of Canada. Canadian Wildife Service. Queen's Printer, Ottawa.

Klein, D. R.

1968 The introduction, increase and crash of reindeer on St. Matthew Island. Journal of Wildlife Management 32:350-367.

Klein, D. R., and R. G. White (editors)

1978 Parameters of caribou population ecology in Alaska: Proceedings of a symposium and workshop. Biological Papers of the University of Alaska, Special Report 3 .

Koch, L.

1945 The east Greenland ice. Meddelelser om Grønland 130(2).

Kummerow, J., G. S. McMaster, and D. A. Krause

1980 Temperature effect on growth and nutrient contents in Eriophorum vaginatum under controlled environmental conditions. Arctic and Alpine Research 12:335-341.

Larsen, H., and F. G. Rainey

1948 Ipiutak and the arctic whale hunting culture. Anthropological Papers of the American Museum of Natural History 42. 
Laughlin, C. D., and I. A. Brady (editors)

1978 Extinction and survival in human populations. Columbia Univ. Press, New York.

Lent, P. C.

1966 The caribou of northwestern Alaska. In Environment of the Cape Thompson region, Alaska, edited by N. J. Wilimovsky and J. N. Wolfe, pp. 481-518. U.S. Atomic Energy Commission. U.S. Government Printing Office, Washington, D.C.

Lowenstein, T.

1981 Some aspects of sea ice subsistence hunting in Point Hope, Alaska. Coastal Zone Management Plan, North Slope Borough.

Maher, W. J., and N. J. Wilimovsky

1963 Annual catch of bowhead whales by Eskimos at Point Barrow, Alaska, 1928-1960. Journal of Mammalogy 44:16-20.

Marquette, W. M.

1977 The 1976 catch of bowhead whales (Balaena mysticetus) by Alaskan Eskimos, with a review of the fishery, 1973-1976, and a biological summary of the species. International Whaling Commission's deletion of native exemption for subsistence harvest of bowhead whales, final environmental impact statement. National Oceanic and Atmospheric Administration, U.S. Department of Commerce, Washington, D.C.

Marquette, W. A., and J. R. Bockstoce

1980 Historical shore-based catch of bowhead whales in the Bering, Chukchi, and Beaufort Seas. Marine Fisheries Review 42(9-10):5-19.

Marsh, G. H.

1954 A comparative survey of Eskimo-Aleut religion. Anthropological Papers of the University of Alaska 3:21-36.

Mauss, $M$.

1979 Seasonal variations of the Eskimo: A study in social morphology. Translated by J. J. Fox. Routledge and Kegan Paul, London.

Meldgaard, $M$.

1983 Resource fluctuations and human subsistence: A zoo-archaeological and ethnographical investigation of a west Greenland caribou hunting camp. In Animals and archaeology: I. Hunters and their prey, edited by J. Clutton-Brock and C. Grigson, pp. 259-272. BAR International Series 163.

Milan, F. A.

1964 The acculturation of the contemporary Eskimo of Wainwright, Alaska. Anthropological Papers of the University of Alaska 11(2).

Miller, P. C., W. A. Stoner, and L. L. Tiezen

1976 A model of stand photosynthesis for the wet tundra meadow at Barrow, Alaska. Ecology 57:411-430.

Mitchell, E., and R. R. Reeves

1980 The Alaska bowhead problem: A commentary. Arctic 33:686-723.

Moore, J. A.

1981 The effects of information networks in hunter-gatherer society. In Huntergatherer foraging strategies, edited by B. Winterhalder and E. A. Smith, pp. 194-217. Univ. of Chicago Press, Chicago.

1983 The trouble with know-it-alls: Information as a social and ecological resource. In Archaeological hammers and theories, edited by J. A. Moore and A. S. Keene, pp. 173-191. Academic Press, New York.

Moritz, R. E.

1977 On a possible sea breeze circulation near Barrow, Alaska. Arctic and Alpine Research 9:427-431. 
Moser, T. J., T. H. Nash III, and J. W. Thompson

1979 Lichens of Anaktuvuk Pass, Alaska, with emphasis on the impact of caribou grazing. The Bryologist 82:393-408.

Murdoch, J.

1886 A few legendary fragments from the Point Barrow Eskimo. American Naturalist 20:593-599.

1892 Ethnological results of the Point Barrow expedition. Annual Report of the Bureau of American Ethnology 9(1).

Murie, O. J.

1935 Alaska-Yukon caribou. North American Fauna 54. United States Department of Agriculture, Bureau of Biological Survey, Washington, D.C.

Myers, J. P., and F. A. Pitelka

1979 Variations in summer temperature patterns near Barrow, Alaska: Analysis and ecological interpretation. Arctic and Alpine Research 2:131-144.

Nelson, E. W.

1899 The Eskimo about Bering Strait. Annual Report of the Bureau of American Ethnology 18(1).

Nelson, R. K.

1969 Hunters of the northern ice. Univ. of Chicago Press, Chicago.

Okakok, K. L. (cditor)

1981 Puiguitkaat: The 1978 elder's conference. Commission on History and Culture, North Slope Borough.

Ostermann, H., and E. Holtved (editors)

1952 The Alaskan Eskimos as described in the posthumous notes of Dr. Knud Rasmussen. Eskimo Archaeology and Ethnology, Report of the Fifth Thule Expedition 1921-24, Vol. X. Glydendalske Boghandel, Copenhagen.

Palmer, L. J., and C. H. Rouse

1945 Study of the Alaska tundra with reference to its reactions to reindeer and other grazing. Research Report No. 10. U.S. Department of Interior, Washington, D.C.

Pegau, R. E.

1968 Growth rates of important reindeer forage lichens on the Seward Peninsula. Arctic 21:255-259.

Pewe, T. L.

1975 Quaternary geology of Alaska. U.S. Geological Survey Professional Paper 835.

U.S. Government Printing Office, Washington, D.C.

Piddocke, $\mathrm{S}$.

1965 The potlatch system of the southern Kwakiutl. Southwestern Journal of Anthropology 21:244-264.

Porter, R. P.

1893 Report on population and resources of Alaska at the eleventh census: 1890. Department of the Interior, Census Office. U.S. Government Printing Office, Washington, D.C.

Porter, S. C., and G. H. Denton

1967 Chronology of neoglaciation in the North American Cordillera. American Journal of Science 265:117-210.

Rainey, F. G.

1947 The whale hunters of Tigara. Anthropological Papers of the American Museum of Natural History 41(2).

Rappaport, R. A.

1971 Ritual, sanctity, and cybernetics. American Anthropologist 73:59-76.

1979 Ecology, meaning, and religion. North Atlantic Books, Richmond, Calif. 
Rasmussen, K. J. V.

1927 Across arctic America. Putnam, New York.

Rausch, R.

1951 Notes on the Nunamiut Eskimo and mammals of the Anaktuvuk Pass region. Brooks Range, Alaska. Arctic 4:147-195.

Ray, P. H.

1885 Report of the International Polar Expedition to Point Barrow, Alaska. U.S. Government Printing Office, Washington, D.C.

Reimers, E.

1982 Winter mortality and population trends of reindeer on Svalbard, Norway. Arctic and Alpine Research 14:295-300.

Rink, $\mathrm{H}$.

1875 Tales and traditions of the Eskimo. Blackwood, London.

Rogers, J. C.

1978 Meteorological factors affecting interannual variability of summertime ice extent in the Beaufort Sea. Monthly Weather Review' 106:890-897.

Root, D.

1983 Information exchange and the spatial configurations of egalitarian societies. In Archaeological hammers and theories, edited by J. A. Moore and A. S. Keene, pp. 193-219. Academic Press, New York.

Saario, D. J. and B. Kessel

1966 Human ecological investigations at Kivalina. In Environment of the Cape Thompson region, Alaska, ediled by N. J. Wilimovsky and J. N. Wolfe, pp. 969-1040. United States Atomic Energy Commission. U.S. Government Printing Office, Washington, D.C.

Sahlins, M.

1972 Stone age economics. Aldine, New York.

Scheffer, V. B.

1951 The rise and fall of a reindeer herd. Scientific Monthly 73:356-362.

Sheehan, G. W.

1985 Whaling as an organizing focus in northwestern Alaskan Eskimo society. In Prehistoric hunter-gatherers: The emergence of cultural complexity, edited by T. D. Price and J. A. Brown, pp. 123-154. Academic Press, New York.

Simpson, R. N.

1875 The western Eskimo. In A selection of papers on arctic geography and ethnology. The Arctic Expedition of 1875, Royal Geographic Society. Murray,

Skoog, R. O. London.

1968 Ecology of the caribou (Rangifer tarandus granti) in Alaska. Ph.D. thesis, Univ: of California, Berkeley.

Smith, J. G. E.

1978 Economic uncertainty in an "original affluent society": Caribou and caribou eater Chipewyan adaptive strategies. Arctic Anthropology 15:68-88.

Solecki, R. S.

1951 Archaeology and ecology of the arctic slope of Alaska. Annual Report of the Smithsonian Institution (1950), pp. 469-495.

Spencer, R. F.

1959 The north Alaskan Eskimo: A study in ecology and society. Smithsonian Institution, Bureau of American Ethnology Bulletin 171.

1972 The social composition of the north Alaskan whaling crew. In Alliance in Fskimo society, edited by L. Guemple, pp. 110-120. Proceedings of the American Ethnological Society, 1971, Supplement. Univ. of Washington Press, Seattle. 
Stanford, D. J.

1976 The Walakpa site: Its place in the Birnirk and Thule cultures. Smithsonian Contributions to Anthropology 20. Smithsonian Institution Press, Washington, D.C.

Stefansson, V.

1919 The Stefansson-Anderson Arctic Expedition of the American Museum: Preliminary ethnological report. Anthropological Papers of the American Museum of Natural History 14(1).

1922 My life with the Eskimo. Macmillan, New York.

Tiezen, L. L.

1973 Photosynthesis and respiration in arctic tundra grasses: Field light intensity and temperature responses. Arctic and Alpine Research 5:239-251.

Vansina, J.

1971 Once upon a time: Oral traditions as history in Africa. Daedalus 100:442-468.

Van Stone, J. W.

1962 Point Hope: An Eskimo village in transition. Univ. of Washington Press, Seattle.

Vibe, $\mathrm{C}$.

1967 Arctic animals in relation to climatic fluctuations. Meddelelser om Grønland 170(5).

White, R. G., and J. Trudell

1980 Habitat preference and forage consumption by reindeer and caribou near Atkasook, Alaska. Arctic and Alpine Research 12:511-529.

Winterhalder, B.

1981 Optimal foraging strategies and hunter-gatherer research in anthropology: Theory and models. In Hunter-gatherer foraging strategies, edited by B. Winterhalder and E. A. Smith, pp. 13-35. Univ. of Chicago Press, Chicago.

Winterhalder, B., and E. A. Smith (editors)

1981 Hunter-gatherer foraging strategies. Univ. of Chicago Press, Chicago.

Wobst, $\mathrm{M}$.

1974 Boundary conditions of paleolithic social systems: A simulation approach. American Antiquity 39:147-78.

1976 Locational relationships in paleolithic society. Journal of Human Evolution.

1977 Stylistic behavior and information exchange. In For the Director: Research essays in honor of James B. Griffin, edited by C. E. Cleland, pp. 317-342. University of Michigan Museum of Anthropology, Anthropological Papers 61 .

World Meteorological Organization

1971-1977 Monthly Climatic Data for the World 24-30. U.S. Environmental Data Service, National Oceanic and Atmospheric Administration. National Climatic Center, Asheville, N.C.

World Weather Records 1931-1940

1947 Smithsonian Miscellaneous Collections 105. Smithsonian Institution, Washington, D.C.

World Weather Records 1941-1950

1959 Weather Bureau, U.S. Department of Commerce. U.S. Government Printing Office, Washington, D.C.

World Weather Records 1951-1960

1966 Vol. 1, North America. National Oceanic and Atmospheric Administration. U.S. Department of Commerce. U.S. Government Printing Office, Washington, D.C.

World Weather Records 1961-1970

1979 Vol. I, North America. National Oceanic and Atmospheric Administration, U.S. Department of Commerce. U.S. Government Printing Office, Washington, D.C. 